\title{
A situação da pesca artesanal nas regiões brasileiras
}

\author{
Hugo Fogliano Gonçalves" \\ Edson Lopes Guedes Filho*** \\ Kacia Castelo Branco Chaves**** \\ Dayane Aparecida dos Santos ${ }^{* * * * *}$
}

\section{Resumo}

A pesca assume importante papel na economia brasileira; oferece mão de obra e renda, além de alimento para população. Porém, os dados estatísticos sobre a pesca marinha no Brasil são insuficientes, por ser uma atividade basicamente extrativista, descentralizada e cercada de grande informalidade. Um dos principais problemas enfrentados é a quantificação da sua importância econômica. Por isso, o presente trabalho reúne e analisa os dados da produção de peixes nas regiões brasileiras, na época de 2000 a 2007. Os resultados permitem situar o contexto nacional da produção da pesca, de forma que podem ser observadas as regiões que mais produziram, destacando a pesca artesanal do Norte e Nordeste do país.

Palavras-chave: Pesca. Regiões brasileiras. Dados estatísticos.

* Professor da Universidade Federal Rural do Rio de Janeiro. Mestre Eng. Produção - Coppe/UFRJ.

*** MBA Gestão Estratégica de Negócios Universidade Federal Fluminense - UFF.

**** Professora da Universidade Federal Rural do Rio de Janeiro. Mestre Gestão e Estratégia em Negócios/UFRRJ.

*:**: Acadêmica do Curso de Zootecnia da Universidade Federal Rural do Rio de Janeiro.

http://dx.doi.org/10.5335/rtee.v20i42.4479

Submissão: 16/08/2013. Aceite: 11/07/2014. 


\section{Introdução}

A pesca é uma forma de trabalho e uma atividade econômica das mais antigas na história do homem. No território brasileiro, antes do descobrimento, já havia diferentes grupos de índios que praticavam a pesca na forma de subsistência (DIEGUES, 1983). No Brasil, a pesca foi influenciada por uma variada gama de culturas, tendo por base a cultura portuguesa e espanhola. O legado deixado por essas culturas permitiu o surgimento no litoral de culturas ligadas à pesca como, por exemplo, a do jangadeiro - que abrange o litoral nordestino indo do Ceará à Bahia, o caiçara - que abrange o litoral entre o Rio de Janeiro e São Paulo, e a do açoriano que abrange o litoral de Santa Catarina até o Rio Grande do Sul (DIEGUES, 1999).

A precariedade das estatísticas da pesca artesanal, tanto no Brasil quanto no mundo, é amplamente reconhecida. No Brasil, a pesca artesanal sofre de uma carência de informações biológicas e socioeconômicas. Durante a vigência da Superintendência de Desenvolvimento da Pesca ( Sudepe), os dados e informações sobre a atividade da pesca artesanal eram precários, mas com a extinção do órgão, em 1989, essas se tornaram ainda mais precárias. Uma das carências detectadas eram as informações socioeconômicas dos trabalhadores do mar, as tecnologias de pesca, o saber tradicional dos pescadores e as formas de organização social dos pescadores artesanais.

Há ao longo do litoral brasileiro várias formas de organização do processo da pesca artesanal, sendo essas a pesca de subsistência, a pesca nos moldes da produção mercantil e a pesca capitalista. A pesca de subsistência está praticamente extinta no litoral, mas com algumas ocorrências no amazonas e entre as tribos indígenas e também entre algumas populações ribeirinhas. Ela é mais uma economia de troca, em que o uso de moeda não é observado, e o eventual excedente é muito reduzido. A pesca, nos moldes da pequena produção mercantil, tem a sua forma de organização na produção do pescado e nos moldes de sua comercialização. Há certa forma de organização e divisão social do trabalho. O princípio que rege a organização da produção é o de mercadoria, que se transforma em dinheiro. A pesca capitalista apresenta as seguintes características: a propriedade e/ou posse dos instrumentos de produção, a forma de remuneração é o salário, o pescador não tem autonomia de tomada de decisão e nem sobre os outros aspectos da pescaria, os equipamentos modernos tais como o sonar, o radar e a ecossonda transformam completamente a função do mestre da pesca, e a atividade é voltada para a produção de mercadoria, e a reposição da força de trabalho é mediante salário. 
O ambiente marinho brasileiro é composto por $7.378 \mathrm{~km}$ de extensão e abrange 17 estados, ocorrendo uma grande diversidade de ambientes: estuários, lagoas, costeiras, manguezais, marismas, praias e costões rochosos com fundos arenoso, lodosos, recifes de algas calcárias e biodetritos, da plataforma continental e do talude superior (HAINOVICI, 2011). Dessa forma, os tipos de fundos associados às correntes marinhas que banham a costa brasileira tem determinado o nível de produtividade primária da pesca, seja em biotas tropicais ou subtropicais e com temperaturas de alta diversidade, o que tem propiciado a ocorrência de vários recursos pesqueiros que são explorados, utilizando-se uma gama variada de apetrechos e de modalidades de pesca, seja em pequena escala, com ou sem embarcação, ou em escala que inclui a utilização de grandes embarcações.

O presente trabalho compara a situação da pesca entre as regiões brasileiras, demonstrando as disparidades em termos de produtividade. Analisando os dados da Tabela 19 - Pesca Extrativa - Regiões, observamos que a região Nordeste tem nove estados, com produção de 447.603,5 toneladas de pescado e com uma extensão marítima de $3.317 \mathrm{~km}$. A região Norte conta com dois estados com produção de $428.952,50$ toneladas de pescado e com uma extensão marítima de $1.1160 \mathrm{~km}$.

A região sudeste tem três estados com produção de 784.679 toneladas de pescado e com uma extensão marítima de $1.650 \mathrm{~km}$. A região Sul tem três estados com produção de 949.645 toneladas de pescado e com uma extensão marítima de $1.251 \mathrm{~km}$. Comparando a extensão marítima do Nordeste com as demais regiões, observa-se que a região Norte tem $34,9 \%$ da extensão marítima do Nordeste e consegue ter uma produtividade de $95,83 \%$ a mais. Já a região Sudeste que tem $49,74 \%$ da extensão marítima do Nordeste, consegue ter uma produtividade de $175,31 \%$ a mais. E a região Sul com $37,71 \%$ da extensão marítima do Nordeste, consegue ter uma produtividade de $212,16 \%$ a mais. Com base nesses dados, será possível melhorar a produção para que ela seja mais rentável na região Nordeste, otimizando o fomento governamental para maior e melhor desenvolvimento da pesca.

\section{Material e métodos}

Os dados necessários para a elaboração desse trabalho foram coletados dos anuários estatísticos do Ibama. Em termos de métodos, eles foram selecionados e compilados para uma planilha em excel e, partir desse software, foram feitas as diversas combinações de dados para obter as mais diversas planilhas para a análise e a elaboração de gráficos e de tabelas. 


\section{Resultados e discussões}

Analisando os dados referentes à pesca, entre os anos de 2000 e 2007, observa-se pela Tabela 1 que a pesca artesanal produziu $47,67 \%$ do total da produção, enquanto que a pesca industrial produziu apenas $27,59 \%$ no total da produção nacional. Esses dados mostram claramente que, durante sete anos, a pesca artesanal tem sido responsável por colocar o pescado na mesa do povo brasileiro. Esses dados também mostram que a soma da produção das regiões Norte e Nordeste ultrapassa em mais de $200 \%$ a produção das regiões Sudeste e Sul juntas, e a produção da pesca artesanal do Norte e Nordeste é superior em um pouco mais de $40 \%$ do total da produção da pesca industrial em todas as regiões do Brasil.

Tabela 1 - Produção em tonelada de pescado entre os anos 2000 e 2007

\begin{tabular}{l|c|c|c|c}
\hline \multicolumn{5}{c}{ Produção de pescado por região - ton. 2000 a 2007 } \\
\hline & Pesca industrial & Pesca artesanal & Aquicultura & Total \\
\hline Norte & $18.882,50$ & $177.040,00$ & $26.343,00$ & $222.265,50$ \\
Nordeste & $8.203,00$ & $215.922,50$ & $107.486,00$ & $331.611,50$ \\
Sudeste & $99.125,00$ & $60.742,00$ & $36.661,50$ & $196.528,50$ \\
Sul & $151.154,00$ & $25.576,50$ & $78.350,00$ & $255.080,50$ \\
Totais & $277.364,50$ & $479.281,00$ & $248.840,50$ & $1.005 .486,00$ \\
Percentuais & $27,59 \%$ & $47,67 \%$ & $24,75 \%$ & $100 \%$ \\
\hline
\end{tabular}

Fonte: Estatística da Pesca 2001 - Dados compilados pelo autor.

Em termos de produção acumulada de pescado, a região Norte apresentou uma pequena oscilação de crescimento e, nos período entre os anos de 1996 e 1999, houve um aumento significativo de $41,31 \%$. Nos anos seguintes, a produção não acompanhou o crescimento dos anos anteriores e o aumento ficou em 8,48\%. Já para os últimos anos verificados na Tabela 5 , a produção foi negativa na razão de $-5,55 \%$.

O pescado brasileiro está entre as quatro maiores fontes de fornecimento de proteína animal para a alimentação humana. A produção nacional de pescado no ano de 2007 atingiu o total de 1.056.149 toneladas. Observando-se o Gráfico 1, verifica-se que a pesca artesanal representa $46 \%$ do total da produção nacional, a aquicultura representa $27 \%$ e a pesca industrial está representando $26 \%$. Por um lado, esses dados confirmam que a pesca artesanal é a grande responsável pelo pescado consumido no Brasil. Porém, os subsídios de governo apenas beneficiam a 
pesca industrial. Mas por, outro, cabe aos pescadores artesanais e aos aquicultores se organizarem de forma mais profissional e competitiva, para que possam ter acesso a tais recursos para criarem mecanismos de competitividade e, principalmente, afastarem o intermediário da cadeia de comercialização do pescado.

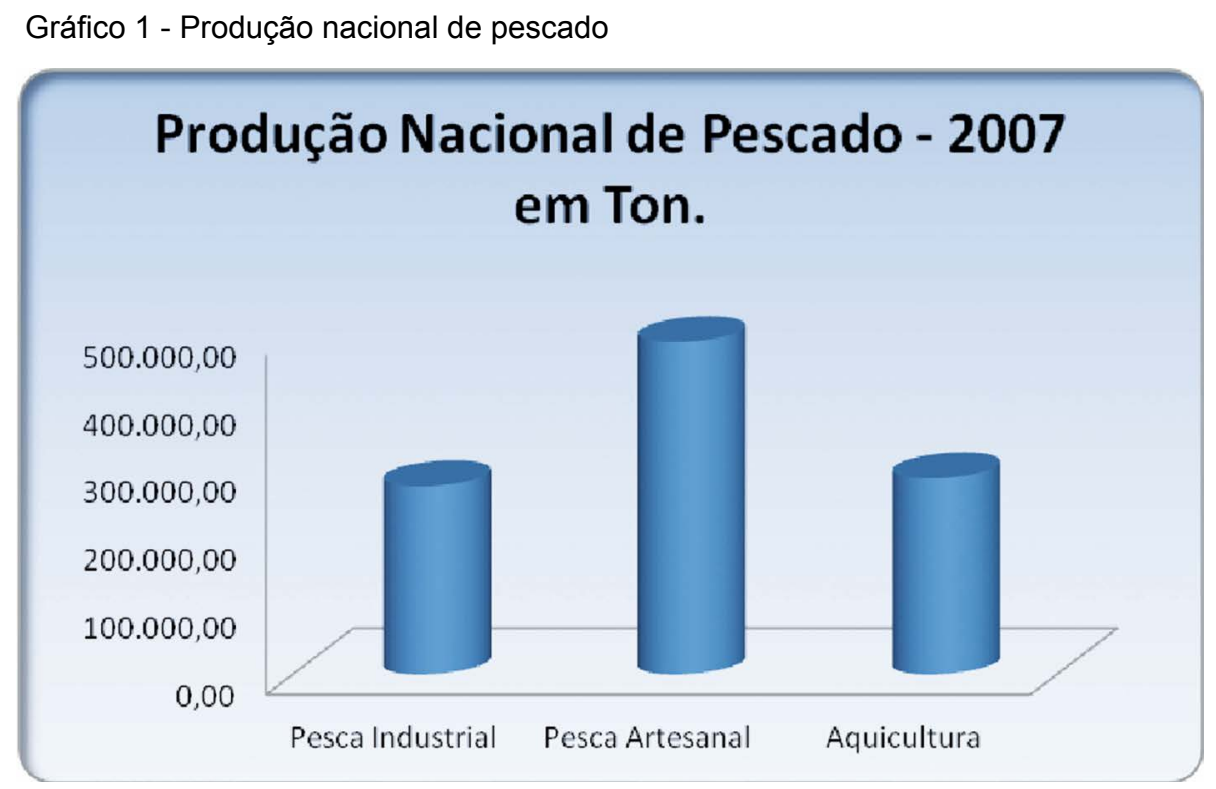

Fonte: Estatística da Pesca 2007 - Ibama - Dados trabalhado pelo autor.

Atualmente, o setor da pesca brasileira tem contribuído com a geração de 800 mil empregos formais. E tem um parque industrial que abrange 300 empresas. Porém, diferentemente de outras áreas de produção, os recursos pesqueiros não aparecem como um produto do trabalho humano, a reprodução se realiza segundo as leis da reprodução biológica que escapam ao controle do homem (MARRUL FILHO, 2001). Os recursos pesqueiros estão com seus estoques em um padrão insustentável de desenvolvimento para o da atividade pesqueira. (DIEGUES, [s. d.]).

A reprodução biológica em combinação com o crescimento das espécies de pescado é um fenômeno indispensável para a renovação e a ampliação dos estoques dos recursos pesqueiros. Sem o respeito a esse fenômeno biológico, não há como se construir um teto máximo sob o qual a atividade pesqueira possa operar. No ano de 1999 a situação sobre o estado de explotação dos recursos pesqueiros tem sido objeto de avaliações constantes e desde 1990, essa situação, praticamente, não se alterou, confirmando que $44 \%$ das principais pescarias mundiais estão totalmente 
exploradas, portanto, o nível de captura de pescados está no máximo ou muito próximo disso, consequentemente, não se prevê margem para expansão das capturas.

Quanto à pesca no Brasil, essa também está atravessando uma crise e os aspectos mais visíveis podem ser observados na situação da sobrepesca em que se encontram os pescados mais importantes (MARRUL FILHO, 2001). Uma das causas da sobrepesca pode ser a falência do setor pesqueiro nacional, que está aliada aos baixos rendimentos que tornam a pescaria economicamente inviável. O comprometimento dos principais recursos pode ser oriundo de políticas públicas que foram alocadas ao setor da pesca de forma inadequada e que estavam associadas ao imediatismo, como também à participação inadequada dos atores sociais envolvidos na pesca e também à aparente incapacidade do Estado em realizar uma reversão desse quadro. A pesca artesanal, embora fosse responsável por uma parcela significativa, em termos de captura, recebia escassos recursos e passava a sofrer pressão da pesca industrial cujos barcos invadiam as regiões que se encontravam interditadas, causando a devastação dos recursos pesqueiros.

Segundo Fourez (1994), o conhecimento é verdadeiro quando permite realizar os projetos que temos em mente e adaptá-los às possibilidades. De certa forma, isso significa que os objetivos não devem ser construídos de qualquer modo, mas de forma que nossos planos possam se tornar realidade. Olhando as notícias que estão sendo veiculadas, em especial pela Empresa Brasil de Comunicação, em artigo publicado em 15 de outubro de 2007 sob o título Rios, lagos e reservatórios da União poderão ser usados para criação de peixes no qual afirma que, segundo a Organização das Nações Unidas para Agricultura e Alimentação - FAO, o Brasil, até 2030 , pode produzir 20 milhões de toneladas de pescado anuais. Analisando a frase "o conhecimento é verdadeiro quando permite realizar os projetos que temos em mente e adapta-los às possibilidades", percebe-se que o governo não conhece a sua realidade ou não tem conhecimento sobre a real situação da pesca e aquicultura brasileira. Para construir um patamar que possa tornar o Brasil altamente competitivo em produção de pescado (pesca e/ou aquicultura) será necessário investir, não somente na produção, mas também em organização social de pescadores e aquicultores, em sistemas de transportes e em canais de comercialização, implantação de agroindústrias regionais para agregar valor ao pescado, além de investir maciçamente nas universidades públicas para realizarem pesquisas voltadas às tecnologias de ponta e à tecnologia social 
Tabela 2 - Produção nacional de escado

\begin{tabular}{c|c|c|c|c}
\hline \multicolumn{5}{|c}{ Produção do setor da pesca } \\
\hline Período & Produção no decênio & \multicolumn{2}{c}{ Extremos do decênio } & $\%$ de Crescimento \\
\hline 1950 a 1960 & 2.130 .900 & 153.100 & 251.000 & $64 \%$ \\
1961 a 1970 & 4.121 .424 & 275.100 & 573.021 & $108 \%$ \\
1971 a 1980 & 7.192 .034 & 613.442 & 804.869 & $31 \%$ \\
1981 a 1990 & 8.504 .956 & 805.771 & 619.805 & $-23 \%$ \\
1991 a 2000 & 6.349 .371 & 648.120 & 666.846 & $3 \%$ \\
2001 a 2010 & 7.659 .545 & 730.378 & 785.369 & $8 \%$ \\
\hline Total & 35.958 .230 & \multicolumn{3}{|c}{} \\
\hline
\end{tabular}

Fonte: http://www.fao.org/figis/servlet/SQServlet?file=/work/FIGIS/prod/webapps/figis/temp/hqp_7253566199911260777. $\mathrm{xml} \&$ outtype $=\mathrm{html}$. Dados trabalhados pelo autor.

Ao analisar os dados de produção de pescado entre os anos de 1950 e 2010 (Tabela 2), percebe-se que a produção brasileira de pescado é bem tímida. No primeiro decênio de 1950 a 1960, a produção de pescado cresceu apenas $64 \%$. No decênio seguinte, houve um "boom" de produção que atingiu 108\% de produção. Mas nos, decênios seguintes, a produção caiu vertiginosamente, alcançando crescimento negativo. No último decênio, a produção alcançou apenas $8 \%$ de crescimento.

A pesca extrativa enfrenta uma séria crise dos estoques, uma vez que os principais recursos pesqueiros estão em situação de máxima capacidade da explotação (FAO, 2009) e, segundo Marrul Filho (2001,), 4\% das principais pescarias mundiais estão totalmente explotadas e, portanto, as capturas se encontram no nível máximo ou próximo desse. Ainda de acordo com Dias-Neto e Dornelles, (1996), os resultados obtidos com as medidas de regulamentação adotadas conseguiram, no máximo, adiar o agravamento da sobrepesca ou o colapso de algumas pescarias, sem, contudo ter revertido sua situação a patamares satisfatórios. Há ainda relatos de Yesaki, (1973), Matsuura (1995), Dias Neto e Mesquita (1988), Castello e Haimovici (1991) sobre a situação da pesca em nível mundial que se encontra em situação de extrema tensão sobre os estoques pesqueiros.

No Brasil, há 17 estados produtores de pesca extrativa, que juntos somam 7.378 de $\mathrm{km}$ de litoral, uma zona econômica exclusiva - ZEE de mais de 4,3 milhões de $\mathrm{km}^{2}$, população de pescadores na ordem de 853.231 (pescadores e aquicultores). $\mathrm{Na}$ análise dos estados produtores de pesca extrativa, foram selecionadas as espécies que apresentaram mais de 100 toneladas a cada ano. As séries históricas estão entre os anos de 2001 e 2007, e, nesse período, a produção atingiu a ordem de 
2.868.225 toneladas e, em termo de crescimento, a média, nesses sete anos, ficou negativa em $-0,37 \%$ (Tabela 3 ).

Tabela 3 - Série histórica da produção de pescado

\begin{tabular}{l|c|c}
\hline \multicolumn{3}{|c}{ Produção de pescado } \\
\hline 2001 & $452.299,00$ & Crescimento \\
2002 & $415.171,00$ & $-8,21 \%$ \\
2003 & $379.414,00$ & $-8,61 \%$ \\
2005 & $391.009,50$ & $3,06 \%$ \\
2006 & $378.929,50$ & $-3,09 \%$ \\
2007 & $415.165,00$ & $9,56 \%$ \\
Total & $436.237,00$ & $5,08 \%$ \\
\hline
\end{tabular}

Fonte: Estatística da Pesca de 2000 a 2007 - Ibama - Dados trabalhado pelo autor.

\subsection{Região Norte}

Na região Norte, há apenas dois estados com costa marítima, Amapá, possuindo $598 \mathrm{~km}$, e Pará, com $562 \mathrm{~km}$. Na pesca extrativa, foram encontradas oito espécies que tiveram produção constante ao longo dos sete anos, são elas, Pescadinha-gó, Pirapema, Bandeirado, Tainha, Arraia, Corvina, Bagre, Pescada amarela e Gurijuba. As espécies Xixarro e Camurim só apresentaram produção no ano de 2001. As espécies Pargo, Sarda, Pescada-cambuçu tiveram produção a partir de 2005. É interessante observar que, no ano de 2007, todas as espécies tiveram queda de produção em relação ao ano anterior. Em termos de produção, o estado do Amapá produziu 33.687,50 toneladas de pesca extrativa entre os anos de $2001 \mathrm{e}$ 2007 e um crescimento médio de $14,14 \%$ (Tabela 4). 
Tabela 4 - Produção de pesca extrativa Amapá

\begin{tabular}{l|c|c|c|c|c|c|c|c}
\hline \multicolumn{7}{c}{ Amapá } \\
\hline \multicolumn{1}{c|}{ Espécie } & 2001 & 2002 & 2003 & 2004 & 2005 & 2006 & 2007 & Totais \\
\hline Mero & 5,00 & 5,50 & 5,00 & 55,00 & 35,00 & 40,00 & & 145,50 \\
Xareu & & 43,00 & 41,00 & & 38,50 & 42,00 & 33,50 & 198,00 \\
Xixarro & 206,50 & & & & & & & 206,50 \\
Camurim & 217,50 & & & & & & & 217,50 \\
Pargo & 0,00 & & & & 75,50 & 103,00 & 99,00 & 277,50 \\
Pescadinha-gó & 87,00 & 89,00 & 84,50 & 36,00 & 19,50 & 25,50 & 21,50 & 363,00 \\
Pirapema & 57,50 & 55,00 & 52,00 & 27,50 & 70,50 & 75,00 & 64,00 & 401,50 \\
Bandeirado & 78,00 & 75,00 & 71,00 & 8,50 & 48,50 & 75,50 & 63,00 & 419,50 \\
Sarda & & & & & 146,00 & 150,50 & 136,50 & 433,00 \\
Pescada branca & & 236,00 & 224,00 & & & & & 460,00 \\
Robalo & & 219,50 & 208,00 & 22,50 & 55,00 & 27,50 & 22,50 & 555,00 \\
Tainha & 68,00 & 72,00 & 68,50 & 51,00 & 136,50 & 188,00 & 146,00 & 730,00 \\
Arraia & 7,00 & 10,50 & 10,00 & 2,00 & 860,50 & 24,00 & 21,00 & 935,00 \\
Pescada-cambuçu & 0,00 & & & & 919,50 & 53,00 & 42,00 & $1.014,50$ \\
Cação & 198,50 & 204,00 & 194,00 & & 406,50 & 106,50 & & $1.109,50$ \\
Urutinga & & 26,00 & 24,50 & 473,50 & 503,50 & 793,50 & 743,50 & $2.564,50$ \\
Corvina & 61,50 & 60,00 & 57,00 & 777,50 & 51,00 & 880,00 & 817,00 & $2.704,00$ \\
Bagre & 393,00 & 395,00 & 375,00 & $1.052,50$ & 860,50 & $1.265,50$ & $1.233,00$ & $5.574,50$ \\
Pescada-amarela & 759,00 & 765,00 & 727,50 & 838,50 & 853,50 & $1.345,50$ & $1.313,50$ & $6.602,50$ \\
Gurijuba & $1.462,00$ & $1.465,00$ & $1.391,50$ & 979,00 & 603,00 & $1.545,50$ & $1.329,50$ & $8.775,50$ \\
Totais & $3.600,50$ & $3.720,50$ & $3.533,50$ & $4.323,50$ & $5.683,00$ & $6.740,50$ & $6.085,50$ & $33.687,00$ \\
\hline Crescimento & & $3 \%$ & $-5 \%$ & $22 \%$ & $31 \%$ & $19 \%$ & $-10 \%$ & Media \\
& & & & & & & & $14,14 \%$ \\
\hline Fon & & & & & & & \\
\hline
\end{tabular}

Fonte: Estatística da Pesca de 2000 a 2007 - Ibama - Dados trabalhado pelo autor.

Na pesca extrativa do estado do Pará (Tabela 5) foram encontradas 22 espécies que tiveram produção constante ao longo dos sete anos, são elas, Guaiba, Canguira, Cavala, Peixe-Pedra, Beijupira, Cangata, Cambeua, Pescada-Cambuçu, Garoupa, Cioba, Arraia, Pirapema, Tainha, Tombira, Bagre, Corvina, Pescadinha-gó, Parco, Tubarão, Serra, Gurijuba, Pescada-amarela. As espécies Albacorinha, Cação, Pescada-branca e Xixarro, só apresentaram produção no ano de 2002. A espécie Xangó teve produção somente no ano de 2001. É interessante observar que, das 40 espécies com produção, apenas dez delas obtiveram aumento de safra da pesca de 2006 para 2007, as demais espécies tiveram queda de produção em relação ao ano anterior. Em termos de produção, o estado do Pará produziu 395.265,50 toneladas de pescado entre os anos 2001 e 2007 e, em termos globais, a produção de pesca extrativa nesse estado tem sido negativa, na média de $-7,62 \%$. 
Tabela 5 - Produção de pesca extrativa Pará

\begin{tabular}{|c|c|c|c|c|c|c|c|c|}
\hline \multicolumn{9}{|c|}{ Pará } \\
\hline Espécie & 2001 & 2002 & 2003 & 2004 & 2005 & 2006 & 2007 & Totais \\
\hline Albacorinha & 0,00 & 102,00 & 0,00 & 0,00 & 0,00 & 0,00 & 0,00 & 102,00 \\
\hline Jurupiranga & 0,00 & 0,00 & 0,00 & 0,00 & 139,00 & 0,00 & 139,00 & 278,00 \\
\hline Cação & 0,00 & 312,50 & 0,00 & 0,00 & 0,00 & 0,00 & 0,00 & 312,50 \\
\hline Enchova & 193,00 & 0,00 & 165,00 & 0,00 & 0,00 & 0,00 & 0,00 & 358,00 \\
\hline Xangó & 707,00 & 0,00 & 0,00 & 0,00 & 0,00 & 0,00 & 0,00 & 707,00 \\
\hline Espadarte & 163,00 & 823,00 & 0,00 & 0,00 & 0,00 & 67,50 & 0,00 & $1.053,50$ \\
\hline Pacamão & 0,00 & $1.095,50$ & 0,00 & 0,00 & 108,00 & 0,00 & 108,00 & $1.311,50$ \\
\hline Camurim & $1.661,00$ & 0,00 & 0,00 & 0,00 & 0,00 & 0,00 & 0,00 & $1.661,00$ \\
\hline Pescada branca & 0,00 & $2.335,00$ & 0,00 & 0,00 & 0,00 & 0,00 & 0,00 & $2.335,00$ \\
\hline Guaiúba & 255,50 & 971,50 & 321,00 & 118,00 & 328,00 & 328,00 & 424,50 & $2.746,50$ \\
\hline Mero & $1.175,00$ & $1.054,50$ & 465,00 & 179,00 & 81,00 & 114,00 & 0,00 & $3.068,50$ \\
\hline Bonito & 206,00 & 0,00 & 856,00 & 497,50 & 565,50 & 555,00 & 597,50 & $3.277,50$ \\
\hline Canguira & 319,00 & 603,00 & 632,00 & 394,00 & 706,00 & 449,50 & 459,50 & $3.563,00$ \\
\hline Cavala & 507,50 & 666,00 & 775,00 & 513,50 & 477,50 & 289,50 & 351,00 & $3.580,00$ \\
\hline Peixe-pedra & 868,00 & $1.130,00$ & 342,00 & 253,50 & 405,50 & 357,50 & 446,50 & $3.803,00$ \\
\hline Beijupirá & 744,00 & 203,50 & 828,50 & 515,50 & 724,00 & 512,50 & 322,00 & $3.850,00$ \\
\hline Cangatá & 810,00 & 528,50 & 577,00 & 897,50 & 643,00 & 757,50 & 822,50 & $5.036,00$ \\
\hline Cambeua & 495,50 & 382,50 & 316,00 & 665,50 & 503,00 & $1.840,00$ & 979,50 & $5.182,00$ \\
\hline $\begin{array}{l}\text { Pescada- } \\
\text { cambuçu }\end{array}$ & 134,00 & $2.945,50$ & 313,50 & $1.071,00$ & 497,50 & 275,50 & 200,50 & $5.437,50$ \\
\hline Garoupa & 542,00 & 891,50 & $1.372,00$ & $1.268,50$ & 743,50 & 522,50 & 253,50 & $5.593,50$ \\
\hline Cioba & $1.100,50$ & 758,00 & 927,00 & 592,50 & 777,00 & 701,00 & 836,50 & $5.692,50$ \\
\hline Xixarro & $6.055,00$ & 0,00 & 0,00 & 0,00 & 0,00 & 0,00 & 0,00 & $6.055,00$ \\
\hline Arraia & 974,00 & 104,50 & $1.433,00$ & $1.220,00$ & $1.242,50$ & 966,50 & 882,00 & $6.822,50$ \\
\hline Pirapema & 948,50 & $3.690,00$ & 664,00 & 661,00 & 494,00 & 448,50 & 229,50 & $7.135,50$ \\
\hline Tainha & $1.619,50$ & $5.284,50$ & 266,00 & 405,50 & 332,50 & 311,50 & 530,50 & $8.750,00$ \\
\hline Robalo & 0,00 & $3.858,00$ & $1.648,00$ & $1.390,50$ & $1.068,00$ & 842,50 & $1.084,00$ & $9.891,00$ \\
\hline Timbira & 356,00 & $5.664,00$ & $1.038,00$ & 678,00 & $1.270,50$ & 925,00 & 736,00 & $10.667,50$ \\
\hline Uricica & $4.175,00$ & $7.988,50$ & 0,00 & 0,00 & 0,00 & 0,00 & 0,00 & $12.163,50$ \\
\hline Bandeirado & $5.255,00$ & 0,00 & $1.965,00$ & $2.970,50$ & $2.333,50$ & $2.455,50$ & $2.421,00$ & $17.400,50$ \\
\hline Bagre & $5.847,50$ & 108,50 & $2.685,00$ & $3.880,50$ & $3.992,50$ & $2.617,50$ & $1.913,50$ & $21.045,00$ \\
\hline Corvina & $3.963,50$ & 786,50 & $3.507,00$ & $3.594,00$ & $4.489,00$ & $3.261,00$ & $2.579,50$ & $22.180,50$ \\
\hline Pescadinha-gó & $3.452,00$ & $3.318,50$ & $3.328,50$ & $3.143,00$ & $1.395,50$ & $2.771,00$ & $5.758,00$ & $23.166,50$ \\
\hline Pargo & $4.925,50$ & $1.149,50$ & $4.993,00$ & $4.900,50$ & $6.803,50$ & $5.649,00$ & $2.814,50$ & $31.235,50$ \\
\hline Tubarão & $5.611,00$ & $6.857,50$ & $5.485,00$ & $4.377,50$ & $5.348,00$ & $3.160,00$ & $3.974,50$ & $34.813,50$ \\
\hline Serra & $6.080,00$ & $4.968,50$ & $6.821,50$ & $6.064,50$ & $5.731,50$ & $5.960,00$ & $4.683,50$ & $40.309,50$ \\
\hline Gurijuba & $12.274,00$ & $1.010,50$ & $8.098,50$ & $7.013,50$ & $5.391,00$ & $3.610,00$ & $4.724,00$ & $42.121,50$ \\
\hline Uritinga & 0,00 & $21.630,50$ & $4.427,00$ & $6.016,50$ & $3.717,50$ & $3.861,50$ & $2.906,50$ & $42.559,50$ \\
\hline Xareu & 0,00 & $70.953,00$ & 662,00 & 620,00 & 525,00 & 398,50 & 638,00 & $73.796,50$ \\
\hline $\begin{array}{l}\text { Pescada- } \\
\text { amarela }\end{array}$ & $17.182,50$ & $1.392,00$ & $21.027,00$ & $16.655,00$ & $14.138,50$ & $13.786,50$ & $14.888,00$ & $99.069,50$ \\
\hline Totais & $71.417,50$ & $81.222,00$ & $54.249,50$ & $53.281,50$ & $50.308,00$ & $43.609,50$ & $41.177,50$ & $395.265,50$ \\
\hline Crescimento & & $13,73 \%$ & $-33,21 \%$ & $-1,78 \%$ & $-5,58 \%$ & $-13,31 \%$ & $-5,58 \%$ & Média $-7,62$ \\
\hline
\end{tabular}

Fonte: Estatística da Pesca de 2000 a 2007 - Ibama - Dados trabalhado pelo autor.

Teoria e Evidência Econômica - Ano 20, n. 42, p. 110-138, jan./jun. 2014 


\subsection{Região Nordeste}

A região Nordeste possui apenas nove estados, todos com litoral marítimo. Alagoas com 229 km, Bahia com 932 km, Ceará com 573 km, Maranhão com 640 km, Paraíba com 117 km, Pernambuco com 187 km, Piauí com 66 km, Rio Grande do Norte com $410 \mathrm{~km}$ e Sergipe com $163 \mathrm{~km}$. Na pesca extrativa do estado de Alagoas, foram encontradas 12 espécies que apresentaram produção constante ao longo da série estudada, são elas Agulha, Arabiana, Cação, Cavala, Vermelho, Serra, Carapeba, Bagre, Manjuba, Pescada, Sardinha e Tainha. As espécies Uritinga, Xangó e Xixarro tiveram produção apenas no ano de 2001. É interessante observar que no ano de 2007 as espécies, Vermelho, Manjuba e Sardinha foram as únicas que tiveram aumento de produção em relação ao ano anterior. O estado de Alagoas produziu 32.203 toneladas de pesca extrativa entre os anos e 2001 e 2007, e um crescimento médio negativo, de $-1,00 \%$ (Tabela 6).

Tabela 6 - Produção de pesca extrativa Alagoas

\begin{tabular}{l|c|c|c|c|c|c|c|c}
\hline \multicolumn{1}{|c}{ Alagoas } \\
\hline \multicolumn{1}{c}{ Especie } & 2001 & 2002 & 2003 & 2004 & 2005 & 2006 & 2007 & Totais \\
\hline Agulha & 34,00 & 48,00 & 100,00 & 87,50 & 76,50 & 90,50 & 50,00 & 486,50 \\
Arabaiana & 19,50 & 14,00 & 105,00 & 56,50 & 77,00 & 223,50 & 64,50 & 560,00 \\
Uritinga & 288,50 & 0,00 & 0,00 & 0,00 & 0,00 & 0,00 & 0,00 & 288,50 \\
Xangó & 431,00 & 0,00 & 0,00 & 0,00 & 0,00 & 0,00 & 0,00 & 431,00 \\
Cação & 137,50 & 71,00 & 76,00 & 65,00 & 143,00 & 202,00 & 27,50 & 722,00 \\
Cavala & 48,00 & 82,00 & 64,00 & 117,50 & 165,00 & 302,00 & 153,00 & 931,50 \\
Xaréu & 0,00 & 273,50 & 182,00 & 242,50 & 146,50 & 216,00 & 206,50 & $1.267,00$ \\
Vermelho & 431,00 & 322,50 & 201,00 & 275,50 & 236,00 & 174,50 & 187,00 & $1.827,50$ \\
Serra & 226,00 & 203,50 & 185,00 & 158,00 & 188,00 & 296,50 & 250,50 & $1.507,50$ \\
Carapeba & 118,50 & 174,50 & 229,50 & 238,50 & 231,00 & 259,50 & 219,50 & $1.471,00$ \\
Xixarro & $1.256,00$ & 0,00 & 0,00 & 0,00 & 0,00 & 0,00 & 0,00 & $1.256,00$ \\
Bagre & 334,50 & 251,00 & 215,50 & 113,00 & 347,50 & 415,50 & 341,00 & $2.018,00$ \\
Manjuba & 347,50 & 258,50 & 218,50 & 324,00 & 231,50 & 311,00 & 397,00 & $2.088,00$ \\
Pescada & 671,00 & 532,50 & 400,50 & 454,00 & 468,00 & 526,00 & 384,50 & $3.436,50$ \\
Sardinha & 624,00 & 468,50 & 587,50 & 594,50 & 674,00 & 382,50 & 858,00 & $4.189,00$ \\
Tainha & 891,00 & 720,00 & $1.294,00$ & $1.182,50$ & $1.766,50$ & $2.576,50$ & $1.292,50$ & $9.723,00$ \\
TOTAL & $5.858,00$ & $3.419,50$ & $3.858,50$ & $3.909,00$ & $4.750,50$ & $5.976,00$ & $4.431,50$ & $32.203,00$ \\
\hline Crescimento & & $-41,63 \%$ & $12,84 \%$ & $1,31 \%$ & $21,53 \%$ & $25,80 \%$ & $-25,85 \%$ & $-1,00 \%$ \\
\hline Fon : Estis\%
\end{tabular}

Fonte: Estatística da Pesca de 2000 a 2007 - Ibama - Dados trabalhado pelo autor. 
Na pesca extrativa do estado da Bahia (Tabela 7), foram encontradas 19 espécies que apresentaram produção constante ao longo da série estudada, são elas Mero, Garajuba, Arabaiana, Bicuda, Guaiúba, Bagre, Cação, Corvina, Ariacó, Manjuba, Albacora, Badejo, Vermelho, Dourado, Agulha, Carapeba, Serra, Tainha e Sardinha. A espécie Garoupa teve produção apenas nos anos de 2006 e 2007 e as espécies Guaraximbora e Cioba tiveram produção no ano de 2005. É interessante observar que, no ano de 2007, apenas dez espécies tiveram aumento de produção em relação ao anterior. Em termos de produção, o estado da Bahia produziu 184.456 toneladas de pesca extrativa entre os anos 2001 e 2007 e um crescimento médio negativo de $-2,22 \%$.

Tabela 7 - Produção de pesca extrativa Bahia

\begin{tabular}{|c|c|c|c|c|c|c|c|c|}
\hline \multicolumn{9}{|c|}{ Bahia } \\
\hline Espécie & 2001 & 2002 & 2003 & 2004 & 2005 & 2006 & 2007 & Totais \\
\hline Garoupa & 0,00 & 0,00 & 0,00 & 0,00 & 0,00 & 836,50 & 83,50 & 920,00 \\
\hline Guaraximbora & 0,00 & 0,00 & 0,00 & 0,00 & $1.012,50$ & 0,00 & 0,00 & $1.012,50$ \\
\hline Papuda & 308,50 & 343,00 & 283,50 & 292,50 & 0,00 & 0,00 & 0,00 & $1.227,50$ \\
\hline Cioba & 0,00 & 0,00 & 0,00 & 0,00 & $1.246,50$ & 0,00 & 0,00 & $1.246,50$ \\
\hline Mero & 287,00 & 319,00 & 25,50 & 26,50 & 903,50 & 134,00 & 261,00 & $1.956,50$ \\
\hline Garajuba & 0,50 & 0,50 & 95,00 & 0,50 & 831,00 & 798,50 & 359,00 & $2.085,00$ \\
\hline Arabaiana & 300,00 & 333,00 & 481,50 & 495,00 & 201,50 & 363,00 & 0,00 & $2.174,00$ \\
\hline Bicuda & 318,00 & 353,50 & 377,50 & 389,00 & 406,00 & 335,50 & 369,00 & $2.548,50$ \\
\hline Xixarro & $2.364,50$ & 0,00 & 0,00 & 0,00 & 36,00 & 54,50 & 313,50 & $2.768,50$ \\
\hline Guaiúba & 22,50 & 25,00 & 162,50 & 167,50 & 39,50 & $1.446,50$ & $1.140,50$ & $3.004,00$ \\
\hline Saramonete & 692,00 & 769,00 & 797,50 & 839,50 & 0,00 & 0,00 & 0,00 & $3.098,00$ \\
\hline Bagre & 514,00 & 571,00 & 399,00 & 411,50 & 817,50 & 80,50 & 542,50 & $3.336,00$ \\
\hline Cação & 357,50 & 397,50 & 565,50 & 582,50 & 405,50 & 712,50 & 461,50 & $3.482,50$ \\
\hline Pescada & 0,50 & 0,50 & 0,50 & 0,50 & $1.218,50$ & $1.141,50$ & $1.270,00$ & $3.632,00$ \\
\hline Corvina & 526,00 & 584,50 & 599,00 & 617,50 & 486,50 & 542,50 & 562,50 & $3.918,50$ \\
\hline Ariacó & 437,00 & 10,50 & 61,00 & 62,50 & 442,50 & $3.715,00$ & 117,00 & $4.845,50$ \\
\hline Manjuba & 678,00 & 753,50 & $1.066,00$ & $1.654,00$ & 0,00 & 479,50 & 312,50 & $4.943,50$ \\
\hline Albacora & $2.944,00$ & 486,00 & 620,50 & 639,00 & 284,00 & 352,00 & 493,50 & $5.819,00$ \\
\hline Badejo & 476,50 & 529,50 & $1.134,00$ & $1.168,00$ & 945,50 & 886,50 & 850,50 & $5.990,50$ \\
\hline Vermelho & 315,00 & 43,00 & 33,50 & 34,50 & $1.677,00$ & $2.031,00$ & $2.145,00$ & $6.279,00$ \\
\hline Dourado & 606,00 & 672,00 & $1.139,50$ & $1.173,50$ & 990,50 & 923,50 & 916,00 & $6.421,00$ \\
\hline Agulha & 496,00 & $3.271,00$ & $1.363,50$ & $1.402,50$ & 116,00 & 459,00 & $1.819,50$ & $8.927,50$ \\
\hline Carapeba & $1.182,00$ & $1.313,00$ & $2.210,00$ & 227,50 & $1.315,50$ & $1.075,50$ & $1.659,50$ & $8.983,00$ \\
\hline Serra & $5.601,00$ & $6.225,50$ & 770,00 & 793,00 & 64,00 & 39,00 & 13,00 & $13.505,50$ \\
\hline Tainha & $1.732,50$ & $1.925,00$ & $2.656,00$ & $2.735,50$ & $1.865,00$ & $1.442,50$ & $3.054,00$ & $15.410,50$ \\
\hline Sardinha & $12.519,50$ & $13.910,50$ & $8.702,00$ & $8.963,00$ & $6.086,00$ & $6.704,00$ & $10.036,00$ & $66.921,00$ \\
\hline TOTAL & $32.678,50$ & $32.836,00$ & $23.543,00$ & $22.675,50$ & $21.390,50$ & $24.553,00$ & $26.779,50$ & $184.456,00$ \\
\hline Crescimento & & $0,48 \%$ & $-28,30 \%$ & $-3,68 \%$ & $-5,67 \%$ & $14,78 \%$ & $9,07 \%$ & $-2,22 \%$ \\
\hline
\end{tabular}

Fonte: Estatística da Pesca de 2000 a 2007 - Ibama - Dados trabalhado pelo autor. 
Na pesca extrativa do estado do Ceará (Tabela 8), foram encontradas 13 espécies que apresentaram produção constante ao longo da série estudada, a saber, Garoupa, Dentão, Guaraximbora, Bagre, Cação, Beijupira, Bonito, Garajuba, Arraia, Serra, Sardinha, Guaiúba e Cavala. A espécie Caico teve produção apenas no ano de 2001. É interessante observar que no ano de 2007 apenas quatro espécies não apresentaram aumento de produção em relação ao ano anterior.O estado do Ceará produziu 52.526,50 toneladas de pesca extrativa entre os anos 2001 e 2007 e um crescimento médio de $11,71 \%$.

Tabela 8 - Produção de pesca extrativa Ceará

\begin{tabular}{|c|c|c|c|c|c|c|c|c|}
\hline \multicolumn{9}{|c|}{ Ceará } \\
\hline Espécie & 2001 & 2002 & 2003 & 2004 & 2005 & 2006 & 2007 & Totais \\
\hline Peroá & 0,00 & 32,00 & 15,50 & 15,50 & 18,50 & 30,00 & 44,50 & 156,00 \\
\hline Vermelho & 0,00 & 15,50 & 26,50 & 52,00 & 25,00 & 32,50 & 77,50 & 229,00 \\
\hline Garoupa & 70,50 & 62,00 & 83,00 & 73,50 & 55,00 & 72,50 & 129,50 & 546,00 \\
\hline Dentão & 79,50 & 96,00 & 61,50 & 64,00 & 138,50 & 127,50 & 241,00 & 808,00 \\
\hline Guaraximbora & 180,00 & 166,50 & 134,50 & 184,50 & 171,50 & 130,50 & 116,00 & $1.083,50$ \\
\hline Caíco & $1.131,00$ & 0,00 & 0,00 & 0,00 & 0,00 & 0,00 & 0,00 & $1.131,00$ \\
\hline Bagre & 143,50 & 126,50 & 215,00 & 193,50 & 160,50 & 165,50 & 159,00 & $1.163,50$ \\
\hline Cação & 124,00 & 135,00 & 302,00 & 240,00 & 320,00 & 215,00 & 273,50 & $1.609,50$ \\
\hline Beijupirá & 170,50 & 183,50 & 222,50 & 296,50 & 346,50 & 270,50 & 224,00 & $1.714,00$ \\
\hline Bonito & 315,50 & 260,00 & 229,00 & 233,50 & 185,00 & 251,50 & 337,00 & $1.811,50$ \\
\hline Garajuba & 249,00 & 264,00 & 384,00 & 344,00 & 200,50 & 413,00 & 527,00 & $2.381,50$ \\
\hline Arraia & 374,50 & 502,00 & 479,00 & 486,00 & 661,50 & 618,00 & 684,00 & $3.805,00$ \\
\hline Serra & 625,00 & 617,00 & 588,50 & 732,50 & 493,00 & 596,50 & 537,50 & $4.190,00$ \\
\hline Sardinha & 911,00 & $1.528,00$ & $1.682,50$ & $1.569,00$ & $1.124,50$ & $1.425,00$ & $1.270,50$ & $9.510,50$ \\
\hline Guaiúba & $1.346,00$ & $1.336,50$ & $1.442,00$ & $1.665,00$ & $2.090,50$ & $1.389,00$ & $1.492,00$ & $10.761,00$ \\
\hline Cavala & $1.303,00$ & $1.259,00$ & $1.773,50$ & $2.257,00$ & $1.880,00$ & $1.564,50$ & $1.589,50$ & $11.626,50$ \\
\hline TOTAL & $7.023,00$ & $6.583,50$ & $7.639,00$ & $8.406,50$ & $7.870,50$ & $7.301,50$ & $7.702,50$ & $52.526,50$ \\
\hline Crescimento & & $-6,26 \%$ & $16,03 \%$ & $10,05 \%$ & $-6,38 \%$ & $-7,23 \%$ & $5,49 \%$ & $1,95 \%$ \\
\hline
\end{tabular}

Fonte: Estatística da Pesca de 2000 a 2007 - Ibama - Dados trabalhado pelo autor.

Na pesca extrativa do estado do Maranhão (Tabela 9), foram encontradas 13 espécies que apresentaram produção constante ao longo da série estudada, quais sejam: Ariacó, Pargo, Gurijuba, Cação, Pescada-branca, Bonito, Sardinha, Arraia, Peixe-pedra, Cangatá, Tainha, Bagre, Corvina e Pescada-amarela. Identificou-se a produção de Camurim apenas no ano de 2001 e as espécies Xareu, Garajuba e Garoupa apresentaram produção a partir do ano de 2003. Nesse estado, as espécies que apresentaram aumento de produção no ano de 2007, em comparação ao ano 
anterior, foram Sardinha, Arraia, Robalo, Peixe-pedra, Cangatá, e Tainha. No que diz respeito à produção, o estado do Maranhão produziu 124.498,50 toneladas de pesca extrativa entre os anos de 2001 e 2007 e um crescimento médio de $1,26 \%$.

Tabela 9 - Produção de pesca extrativa Maranhão

\begin{tabular}{|c|c|c|c|c|c|c|c|c|}
\hline \multicolumn{9}{|c|}{ Maranhão } \\
\hline Espécie & 2001 & 2002 & 2003 & 2004 & 2005 & 2006 & 2007 & Totais \\
\hline Xaréu & 0,00 & 0,00 & 44,50 & 43,50 & 94,00 & 94,50 & 65,00 & 341,50 \\
\hline Garajuba & 0,00 & 0,00 & 112,00 & 111,00 & 67,00 & 116,00 & 55,00 & 461,00 \\
\hline Garoupa & 0,00 & 0,00 & 112,00 & 115,00 & 102,00 & 75,00 & 75,50 & 479,50 \\
\hline Camurim & 695,00 & 0,00 & 0,00 & 0,00 & 0,00 & 0,00 & 0,00 & 695,00 \\
\hline Cambeua & 0,00 & 0,00 & 217,00 & 220,50 & 135,00 & 140,00 & 95,00 & 807,50 \\
\hline Ariacó & 234,00 & 209,00 & 198,50 & 202,00 & 212,00 & 121,50 & 81,00 & $1.258,00$ \\
\hline Pargo & 272,50 & 267,00 & 207,00 & 209,50 & 222,50 & 196,00 & 189,50 & $1.564,00$ \\
\hline Gurijuba & 314,00 & 308,00 & 178,00 & 181,00 & 231,00 & 348,00 & 291,00 & $1.851,00$ \\
\hline Cação & 333,50 & 304,00 & 246,00 & 261,00 & 312,50 & 332,00 & 130,50 & $1.919,50$ \\
\hline Pescada-branca & 275,00 & 273,00 & 252,00 & 256,50 & 371,50 & 527,00 & 256,00 & $2.211,00$ \\
\hline Bonito & 385,00 & 334,00 & 448,00 & 456,00 & 474,50 & 627,00 & 137,50 & $2.862,00$ \\
\hline Sardinha & 268,00 & 225,00 & 871,50 & 887,00 & 253,00 & 457,50 & 467,50 & $3.429,50$ \\
\hline Arraia & 508,50 & 468,00 & 692,50 & 705,00 & 740,50 & 693,00 & 732,50 & $4.540,00$ \\
\hline Robalo & 0,00 & 612,00 & 675,50 & 687,00 & 673,00 & 858,50 & $1.148,00$ & $4.654,00$ \\
\hline Peixe-pedra & 984,50 & 941,00 & 732,00 & 744,50 & 732,50 & $1.042,00$ & $1.553,00$ & $6.729,50$ \\
\hline Cangatá & $2.128,00$ & $2.045,00$ & $1.490,50$ & $1.516,00$ & $1.588,50$ & $1.631,00$ & $2.096,50$ & $12.495,50$ \\
\hline Tainha & $1.852,50$ & $1.571,50$ & $2.020,50$ & $2.054,00$ & $2.673,50$ & $2.337,50$ & $2.835,50$ & $15.345,00$ \\
\hline Bagre & $2.280,00$ & $2.105,00$ & $2.597,00$ & $2.651,00$ & $3.108,00$ & $2.642,50$ & $1.515,00$ & $16.898,50$ \\
\hline Corvina & $2.643,00$ & $2.610,00$ & $2.686,50$ & $2.742,00$ & $3.400,00$ & $2.953,50$ & $2.819,00$ & $19.854,00$ \\
\hline Pescada-amarela & $3.851,00$ & $3.849,00$ & $3.336,00$ & $3.392,50$ & $4.503,00$ & $3.618,50$ & $3.552,50$ & $26.102,50$ \\
\hline TOTAL & $17.024,50$ & $16.121,50$ & $17.117,00$ & $17.435,00$ & $19.894,00$ & $18.811,00$ & $18.095,50$ & $124.498,50$ \\
\hline Crescimento & & $-5,30 \%$ & $6,17 \%$ & $1,86 \%$ & $14,10 \%$ & $-5,44 \%$ & $-3,80 \%$ & $1,26 \%$ \\
\hline
\end{tabular}

Fonte: Estatística da Pesca de 2000 a 2007 - Ibama - Dados trabalhado pelo autor.

Na pesca extrativa do estado do Paraíba (Tabela 10), pelas séries históricas analisadas foi observado que todas as espécies tiveram produção entre os anos de 2001 e 2007. Foi observado que no ano de 2007, houve um aumento negativo em relação ao ano anterior de $36,34 \%$. Nos anos de 2002, 2004 e 2006, verificou-se um aumento de produção em relação ao ano anterior de $2,35 \%, 48,95 \%$ e 8,96\% respectivamente. O estado da Paraíba produziu 1.484 toneladas de pesca extrativa entre os anos de 2001 e 2007, e um crescimento médio negativo de $-8,52 \%$. 
Tabela 10 - Produção de pesca extrativa Paraíba

\begin{tabular}{l|c|c|c|c|c|c|c|c}
\hline \multicolumn{1}{c}{ Espécie } & 2001 & 2002 & 2003 & 2004 & 2005 & 2006 & 2007 & Totais \\
\hline Biquara & 55,0 & 105,0 & 25,5 & 4,0 & 18,5 & 20,5 & 16,0 & 244,5 \\
Garajuba & 33,0 & 21,5 & 10,5 & 76,5 & 63,0 & 0,0 & 47,0 & 251,5 \\
Ariacó & 130,0 & 82,0 & 52,5 & 20,5 & 16,5 & 115,0 & 16,0 & 432,5 \\
Serra & 101,5 & 118,5 & 54,5 & 112,0 & 75,0 & 53,0 & 41,0 & 555,5 \\
TOTAL & 319,5 & 327,0 & 143,0 & 213,0 & 173,0 & 188,5 & 120,0 & 1484,0 \\
Crescimento & & $2,35 \%$ & $-56,27 \%$ & $48,95 \%$ & $-18,78 \%$ & $8,96 \%$ & $-36,34 \%$ & $-8,52 \%$ \\
\hline
\end{tabular}

Fonte: Estatística da Pesca de 2000 a 2007 - Ibama - Dados trabalhado pelo autor.

Na pesca extrativa do estado de Pernambuco (Tabela 11), foram encontradas sete espécies que apresentaram produção constante ao longo da série estudada, sendo elas Bonito, Bagre, Ariacó, Agulha, Cação, Biquara e Saramonete. Nesse estado, apenas a espécie Bagre apresentou aumento de produção no ano de 2007, em comparação ao ano anterior. Em termos globais, esse ano teve um índice de crescimento negativo na ordem de $46,09 \%$ e, em termos de produção, esse estado produziu 8.412 toneladas de pesca extrativa entre os anos 2001 e 2007 e um crescimento médio de $8,91 \%$. Durante o ano de 2005, todas as espécies da série histórica analisadas tiveram aumento de produção em $115,05 \%$ em relação ao ano anterior. Porém, no ano seguinte, houve uma forte queda de produção, atingindo um percentual nesse ano de $-38,03 \%$.

Tabela 11 - Produção de pesca extrativa Pernambuco

\begin{tabular}{l|c|c|c|c|c|c|c|c}
\hline \multicolumn{1}{c}{ Pernambuco } \\
\hline \multicolumn{1}{c|}{ Espécie } & 2001 & 2002 & 2003 & 2004 & 2005 & 2006 & 2007 & Totais \\
\hline Dentão & 52,00 & 21,00 & 21,00 & 0,00 & 62,00 & 70,00 & 0,00 & 226,00 \\
Bonito & 108,00 & 34,00 & 56,00 & 36,50 & 41,50 & 61,50 & 47,50 & 385,00 \\
Bagre & 24,50 & 120,00 & 31,50 & 20,00 & 59,00 & 66,50 & 89,00 & 410,50 \\
Xaréu & 0,00 & 45,50 & 45,00 & 56,00 & 174,00 & 107,50 & 48,00 & 476,00 \\
Ariacó & 149,00 & 49,50 & 80,50 & 47,00 & 82,50 & 76,50 & 57,50 & 542,50 \\
Agulha & 82,50 & 92,50 & 122,50 & 115,50 & 66,00 & 136,50 & 58,50 & 674,00 \\
Cação & 26,00 & 0,00 & 33,00 & 139,00 & 556,00 & 122,50 & 22,50 & 899,00 \\
Biquara & 134,50 & 132,50 & 140,00 & 135,50 & 164,50 & 183,50 & 130,00 & $1.020,50$ \\
Cavala & 0,00 & 96,00 & 64,50 & 197,00 & 544,00 & 150,00 & 10,00 & $1.061,50$ \\
Saramonete & 299,00 & 493,50 & 362,50 & 310,00 & 522,50 & 433,50 & 296,00 & $2.717,00$ \\
TOTAL & 875,50 & $1.084,50$ & 956,50 & $1.056,50$ & $2.272,00$ & $1.408,00$ & 759,00 & $8.412,00$ \\
Crescimento & & $23,87 \%$ & $-11,80 \%$ & $10,45 \%$ & $115,05 \%$ & $38,03 \%$ & $46,09 \%$ & $8,91 \%$ \\
\hline
\end{tabular}

Fonte: Estatística da Pesca de 2000 a 2007 - Ibama - Dados trabalhado pelo autor. 
Na pesca extrativa do estado de Piauí (Tabela 12), foram encontradas apenas duas espécies que tiveram como produção mais de 100 toneladas na série histórica analisada e dessas apenas a espécie Sardinha teve produção durante os sete anos. No ano de 2002, houve um aumento de produção de $920 \%$ em relação ao ano anterior. Porém, nos anos seguintes, a produção teve forte queda e em 2004 e 2005, atingindo os percentuais de $-41,85 \%$ e $-28,57 \%$ respectivamente. No que tange à produção, o estado de Piauí produziu 593 toneladas de pesca extrativa entre os anos 2001 e 2007, com um crescimento médio de $155,15 \%$.

Tabela 12 - Produção de pesca extrativa Piauí

\begin{tabular}{l|c|c|c|c|c|c|c|c}
\hline \multicolumn{1}{c}{ Piauí } \\
\hline \multicolumn{1}{c|}{ Espécie } & 2001 & 2002 & 2003 & 2004 & 2005 & 2006 & 2007 & Totais \\
\hline Pescadinha-gó & 0,00 & 39,50 & 100,00 & 0,00 & 0,00 & 0,00 & 51,00 & 190,50 \\
Sardinha & 10,00 & 62,50 & 56,50 & 91,00 & 65,00 & 86,50 & 31,00 & 402,50 \\
TOTAL & 10,00 & 102,00 & 156,50 & 91,00 & 65,00 & 86,50 & 82,00 & 593,00 \\
Crescimento & & $920,00 \%$ & $53,43 \%$ & $-41,85 \%$ & $-28,57 \%$ & $33,08 \%$ & $-5,20 \%$ & $155,15 \%$ \\
\hline
\end{tabular}

Fonte: Estatística da Pesca de 2000 a 2007 - Ibama - Dados trabalhado pelo autor.

Na pesca extrativa do estado do Rio Grande do Norte (Tabela 13), pelas séries históricas analisadas, foi observado que as espécies que tiveram produção entre os anos 2001 e 2007, a saber: Garoupa, Pescada, Garajuba, Ariacó, Cavala e Sardinha. As espécies Xixarro e Albacora tiveram produção apenas no ano de 2001. A espécie Atum teve produção apenas no ano de 2003 e a espécie Robalo teve produção a partir do ano de 2005. A espécie Cabeçudo teve produção apenas nos anos de 2002 e 2003. Das séries históricas analisadas durante os anos de 2006 e 2007, verificou-se que houve aumento de produção no percentual de 10,06\% e 11,06 respectivamente. O estado do Rio Grande do Norte produziu 40.807 toneladas de pesca extrativa entre os anos de 2001 e 2007, com um crescimento médio de $0,92 \%$. 
Tabela 13 - Produção de pesca extrativa Rio Grande do Norte

\begin{tabular}{l|c|c|c|c|c|c|c|c}
\hline \multicolumn{1}{c}{ Rio Grande do Norte } \\
\hline \multicolumn{1}{c}{ Espécie } & 2001 & 2002 & 2003 & 2004 & 2005 & 2006 & 2007 & Totais \\
\hline Xaréu & 0,00 & 13,00 & 39,50 & 33,50 & 20,00 & 4,50 & 8,00 & 118,50 \\
Atum & 0,00 & 0,00 & 161,50 & 0,00 & 0,00 & 0,00 & 0,00 & 161,50 \\
Robalo & 0,00 & 0,00 & 0,00 & 0,00 & 36,50 & 105,00 & 109,00 & 250,50 \\
Arabaiana & 0,00 & 61,50 & 51,00 & 42,00 & 38,50 & 31,50 & 43,00 & 267,50 \\
Arraia & 47,50 & 51,00 & 0,00 & 41,50 & 73,50 & 80,50 & 58,00 & 352,00 \\
Bagre & 109,00 & 143,00 & 0,00 & 162,50 & 85,50 & 77,00 & 80,50 & 657,50 \\
Garoupa & 84,00 & 76,50 & 208,50 & 21,50 & 109,50 & 149,50 & 35,00 & 684,50 \\
Cabeçudo & 0,00 & 443,00 & 415,50 & 0,00 & 0,00 & 0,00 & 0,00 & 858,50 \\
Pescada & 109,00 & 71,00 & 104,50 & 123,00 & 263,50 & 188,00 & 209,00 & $1.068,00$ \\
Xixarro & $1.338,00$ & 0,00 & 0,00 & 0,00 & 0,00 & 0,00 & 0,00 & $1.338,00$ \\
Garajuba & 214,00 & 221,50 & 201,50 & 143,00 & 237,50 & 249,50 & 267,00 & $1.534,00$ \\
Ariacó & 176,00 & 234,00 & 224,50 & 172,00 & 241,50 & 264,50 & 328,00 & $1.640,50$ \\
Albacora-branca & 0,00 & 306,00 & $1.156,00$ & 78,00 & 115,50 & 81,50 & 88,00 & $1.825,00$ \\
Cavala & 244,00 & 288,00 & 337,50 & 314,50 & 256,00 & 338,50 & 313,00 & $2.091,50$ \\
Albacora & $2.721,50$ & 0,00 & 0,00 & 0,00 & 0,00 & 0,00 & 0,00 & $2.721,50$ \\
Cação & 789,00 & 0,00 & 0,00 & 653,00 & 937,00 & $1.318,50$ & $1.254,50$ & $4.952,00$ \\
Albacora-bandolim & 0,00 & $1.218,00$ & $1.081,00$ & $1.028,00$ & 813,00 & 522,50 & 820,00 & $5.482,50$ \\
Sardinha & 309,00 & 769,50 & $1.168,00$ & $1.439,50$ & 724,00 & 673,00 & 965,50 & $6.048,50$ \\
Albacora-lage & 0,00 & $1.632,00$ & $1.269,50$ & $1.527,00$ & $1.146,50$ & $1.527,00$ & $1.653,00$ & $8.755,00$ \\
TOTAL & $6.141,00$ & $5.528,00$ & $6.418,50$ & $5.779,00$ & $5.098,00$ & $5.611,00$ & $6.231,50$ & $40.807,00$ \\
Crescimento & & $-9,98 \%$ & $16,11 \%$ & $-9,96 \%$ & $-11,78 \%$ & $10,06 \%$ & $11,06 \%$ & $0,92 \%$ \\
\hline Fonte: Estalsion
\end{tabular}

Fonte: Estatística da Pesca de 2000 a 2007 - Ibama - Dados trabalhado pelo autor.

Na pesca extrativa do estado de Sergipe (Tabela 14), pelas séries históricas analisadas, foi observado que todas as espécies tiveram produção entre os anos 2001 e 2007 , ocorrendo aumento de $21,78 \%$ em relação ao ano de 2006 . O estado de Sergipe produziu 2.623,50 toneladas de pesca extrativa, correspondendo a um crescimento médio de $49,39 \%$. 
Tabela 14 - Produção de pesca extrativa Sergipe

\begin{tabular}{l|c|c|c|c|c|c|c|c}
\hline \multicolumn{1}{c}{ Sergipe } \\
\hline Espécie & 2001 & 2002 & 2003 & 2004 & 2005 & 2006 & 2007 & Totais \\
\hline Cavala & 0,50 & 13,00 & 21,00 & 10,50 & 208,00 & 46,50 & 49,00 & 348,50 \\
Corvina & 8,00 & 147,00 & 82,50 & 30,50 & 50,00 & 48,50 & 51,50 & 418,00 \\
Robalo & 0,00 & 58,00 & 102,00 & 36,50 & 113,50 & 143,00 & 179,00 & 632,00 \\
Bagre & 134,00 & 285,00 & 233,00 & 174,00 & 168,00 & 99,50 & 131,50 & $1.225,00$ \\
TOTAL & 142,50 & 503,00 & 438,50 & 251,50 & 539,50 & 337,50 & 411,00 & $2.623,50$ \\
Crescimento & & $252,98 \%$ & $-12,82 \%$ & $-42,65 \%$ & $114,51 \%$ & $-37,44 \%$ & $21,78 \%$ & $49,39 \%$ \\
\hline
\end{tabular}

Fonte: Estatística da Pesca de 2000 a 2007 - Ibama - Dados trabalhado pelo autor.

\subsection{Região Sudeste}

A região Sudeste tem apenas três estados, Espírito Santo que possui $622 \mathrm{~km}$, Rio de Janeiro com 636 km e São Paulo com 622 km de costa marítima. Esta região é a que apresenta uma maior variedade de pesca extrativa.

No estado de Espírito Santo (Tabela 15), foram encontradas 47 espécies, e dessas, o Peixe-Galo e o Xerelete apresentaram produção a partir de 2006, e a espécie Bonito-listrado apresentou produção apenas em 2007. Das séries históricas estudadas, 19 delas tiveram queda de produção, e, em algumas, a queda foi bastante acentuada para o ano de 2007, comparada a do ano anterior. O estado de Espírito Santo produziu 92.489 toneladas de pesca extrativa e teve um crescimento médio de $12,01 \%$. 
Tabela 15 - Produção de pesca extrativa do Espírito Santo

\begin{tabular}{|c|c|c|c|c|c|c|c|c|}
\hline \multicolumn{9}{|c|}{ Espírito Santo } \\
\hline Espécie & 2001 & 2002 & 2003 & 2004 & 2005 & 2006 & 2007 & TOTAIS \\
\hline Pescada & 1,00 & 13,5 & 18,00 & 13,00 & 23,50 & 28,50 & 16,00 & 113,50 \\
\hline Namorado & 15,00 & 4,5 & 11,50 & 27,50 & 21,50 & 21,50 & 15,50 & 117,00 \\
\hline Papa-terra & 2,00 & 0,5 & 25,50 & 16,50 & 15,50 & 18,50 & 43,00 & 121,50 \\
\hline Mero & 7,00 & 118,5 & 0,50 & 0,50 & 0,50 & 0,50 & 0,00 & 127,50 \\
\hline Tainha & 1,00 & 1,5 & 11,50 & 13,50 & 37,50 & 43,50 & 21,50 & 130,00 \\
\hline Ariacó & 0,0 & 0,0 & 136,00 & 3,50 & 2,50 & 2,50 & 6,00 & 150,50 \\
\hline Carapitanga & 118,50 & 0,0 & 0,00 & 0,00 & 14,50 & 20,50 & 0,00 & 153,50 \\
\hline Albacora-branca & 140,0 & 1,0 & 1,00 & 0,50 & 0,50 & 8,50 & 20,50 & 172,00 \\
\hline Parú & 0,00 & 0,0 & 0,00 & 32,50 & 71,00 & 83,50 & 1,00 & 188,00 \\
\hline Galo & 61,00 & 2,5 & 7,00 & 15,00 & 110,50 & 0,00 & 0,00 & 196,00 \\
\hline Batata & 0,00 & 8,5 & 32,00 & 30,50 & 36,50 & 65,00 & 42,50 & 215,00 \\
\hline Cavalinha & 48,00 & 5,0 & 1,00 & 0,50 & 74,00 & 95,00 & 6,50 & 230,00 \\
\hline Palombeta & 20,00 & 51,0 & 29,50 & 1,00 & 0,50 & 0,50 & 137,50 & 240,00 \\
\hline Cherne & 0,00 & 6,0 & 21,50 & 22,00 & 73,00 & 78,50 & 51,00 & 252,00 \\
\hline Olho-de-boi & 27,50 & 56,0 & 28,50 & 29,50 & 30,00 & 30,00 & 58,50 & 260,00 \\
\hline Olhête & 12,00 & 6,5 & 51,00 & 0,00 & 22,50 & 22,50 & 176,00 & 290,50 \\
\hline Agulhão & 9,5 & 34,5 & 82,00 & 0,00 & 0,00 & 0,00 & 195,50 & 321,50 \\
\hline Dentão & 27,50 & 58,5 & 55,00 & 41,00 & 61,00 & 74,50 & 77,00 & 394,50 \\
\hline Sarda & 83,00 & 167,0 & 20,00 & 20,00 & 35,50 & 39,50 & 29,50 & 394,50 \\
\hline Coró & 0,00 & 0,0 & 0,50 & 71,50 & 157,50 & 190,00 & 81,50 & 501,00 \\
\hline Bagre & 334,50 & 4,5 & 5,00 & 17,00 & 70,50 & 80,50 & 6,50 & 518,50 \\
\hline Peixe-galo & 0,00 & 0,0 & 0,00 & 0,00 & 0,00 & 214,00 & 386,50 & 600,50 \\
\hline Bonito-cachorro & 0,00 & 4,5 & 41,50 & 126,50 & 227,00 & 267,00 & 105,00 & 771,50 \\
\hline Xerelete & 0,00 & 0,0 & 0,00 & 0,00 & 0,00 & 121,00 & 790,50 & 911,50 \\
\hline Espadarte & 14,50 & 31,5 & 35,00 & 46,00 & 199,00 & 303,50 & 346,00 & 975,50 \\
\hline Bonito-listrado & 0,00 & 0,0 & 0,00 & 0,00 & 0,00 & 0,00 & $1.033,00$ & $1.033,00$ \\
\hline Cavala & 0,00 & 12,5 & 120,00 & 219,50 & 203,00 & 240,50 & 245,00 & $1.040,50$ \\
\hline Arraia & 0,0 & 159,5 & 168,00 & 192,00 & 192,00 & 212,00 & 182,50 & $1.106,00$ \\
\hline Sardinha & 0,00 & 2,5 & 42,50 & 40,50 & 225,00 & 302,50 & 538,00 & $1.151,00$ \\
\hline Enchova & 1,00 & 0,5 & 11,00 & 9,00 & 251,00 & 352,00 & 691,00 & $1.315,50$ \\
\hline Vermelho & 0,00 & 34,0 & 122,50 & 279,50 & 182,50 & 195,00 & 695,50 & $1.509,00$ \\
\hline Badejo & 0,00 & 149,0 & 264,50 & 274,00 & 255,00 & 285,00 & 313,50 & $1.541,00$ \\
\hline Garoupa & 117,00 & 101,0 & 544,50 & 201,00 & 167,00 & 197,50 & 241,00 & $1.569,00$ \\
\hline Pescadinha-real & 138,00 & 53,0 & 89,00 & 69,50 & 274,00 & 376,00 & 617,00 & $1.616,50$ \\
\hline Xaréu & 0,00 & 24,5 & 94,00 & 379,00 & 468,50 & 568,00 & 466,50 & $2.000,50$ \\
\hline Manjuba & 497,00 & 497,0 & 82,50 & 37,50 & 35,50 & 222,00 & 660,00 & $2.031,50$ \\
\hline Baiacu & 0,00 & 188,5 & 131,50 & 285,50 & 637,00 & 674,50 & 372,00 & $2.289,00$ \\
\hline Guaiúba & 0,00 & 0,0 & 0,00 & 0,00 & $1.212,50$ & $1.363,50$ & 0,50 & $2.576,50$ \\
\hline Cação & 137,50 & 237,0 & 542,00 & 451,00 & 358,00 & 608,50 & 737,00 & $3.071,00$ \\
\hline Xixarro & 129,50 & 93,0 & 344,00 & 616,00 & 479,50 & 579,00 & $1.252,00$ & $3.493,00$ \\
\hline Pargo-rosa & 241,00 & 394,5 & 491,00 & 711,00 & 768,00 & 897,50 & 468,00 & $3.971,00$ \\
\hline Cioba & 0,00 & 443,5 & $1.064,00$ & $1.345,50$ & 225,50 & 271,50 & $1.270,00$ & $4.620,00$ \\
\hline Albacora-lage & 610,0 & 296,0 & 318,00 & 275,50 & 0,00 & 874,00 & $2.612,50$ & $4.986,00$ \\
\hline Atum & 228,0 & 818,0 & $1.243,50$ & $1.067,00$ & $1.067,00$ & $2.013,00$ & 104,00 & $6.540,50$ \\
\hline Dourado & 849,00 & $1.595,5$ & $2.752,50$ & $1.822,00$ & $2.399,50$ & $2.907,00$ & $3.248,00$ & $15.573,50$ \\
\hline Peroá & $6.594,00$ & $7.365,5$ & $2.594,50$ & $1.341,00$ & 772,00 & 732,00 & 797,50 & $20.196,50$ \\
\hline TOTAL GERAL & $10.620,5$ & $13.177,0$ & $11.725,50$ & $10.211,00$ & $11.559,00$ & $15.934,50$ & $19.261,50$ & $92.489,00$ \\
\hline Crescimento & & $24,07 \%$ & $-11,02 \%$ & $-12,92 \%$ & $13,20 \%$ & $37,85 \%$ & $20,88 \%$ & $12,01 \%$ \\
\hline
\end{tabular}

Fonte: Estatística da Pesca de 2000 a 2007 - Ibama - Dados trabalhado pelo autor. 
No estado do Rio de Janeiro (Tabela 16), foram encontradas 87 espécies na pesca extrativa e as espécies Agulhão, Voador, Congro, Albacora, Mororo, Ariaco e Peixe-rei tiveram produção apenas em 2007. As espécies Vermelho, Mero, Pescadinha-gó, Peixe-pedra, Tortinha, tiveram produção apenas em 2006. As espécies Atum, Guaiúba Saramonete, Pacamão, Albacora-bandolim, Timbira, Bonito, Juripiranga, Bandeirado, Pargo, Dentão, Peixe-voador tiveram produção entre 2006 e 2007. A espécie Pilombeta teve produção apenas nos anos 2002 e 2007. A espécie Pirajica apresentou produção em 2001 e 2002. Das 87 espécies da série histórica, 26 delas tiveram queda de produção e, em algumas, a queda foi bastante acentuada para o ano de 2007, em relação ao ano anterior. Em termos de produção, o estado do Rio de Janeiro produziu 531.844,50 toneladas de pesca extrativa e um crescimento médio de $22,24 \%$. É interessante observar que, no ano de 2006 , houve um aumento percentual de 104,53\% em relação ao ano anterior, mas, no ano seguinte, o aumento foi de apenas $18,19 \%$. 
Tabela 16 - Produção de pesca extrativa do Rio de Janeiro

\begin{tabular}{|c|c|c|c|c|c|c|c|c|}
\hline \multicolumn{9}{|c|}{ Rio de Janeiro } \\
\hline Espécie & 2001 & 2002 & 2003 & 2004 & 2005 & 2006 & 2007 & TOTAL \\
\hline Agulhão & 0,00 & 0,00 & 0,00 & 0,00 & 0,00 & 0,00 & 101,50 & 101,50 \\
\hline Atum & 0,00 & 0,00 & 0,00 & 0,00 & 0,00 & 33,50 & 68,00 & 101,50 \\
\hline Guaiúba & 0,00 & 0,00 & 0,00 & 0,00 & 0,00 & 60,00 & 76,00 & 136,00 \\
\hline Pampo & 41,00 & 33,00 & 33,00 & 31,00 & 27,00 & 15,00 & 11,00 & 191,00 \\
\hline Robalo & 58,00 & 28,50 & 30,00 & 28,50 & 30,50 & 37,00 & 24,00 & 236,50 \\
\hline Pilombeta & 0,00 & 209,50 & 0,00 & 0,00 & 0,00 & 0,00 & 42,50 & 252,00 \\
\hline Pirajica & 136,50 & 131,00 & 0,00 & 0,00 & 0,00 & 0,00 & 0,00 & 267,50 \\
\hline Voador & 0,00 & 0,00 & 0,00 & 0,00 & 0,00 & 0,00 & 293,00 & 293,00 \\
\hline Guaravira & 62,00 & 60,50 & 60,00 & 56,50 & 59,00 & 0,00 & 0,00 & 298,00 \\
\hline Saramonete & 0,00 & 0,00 & 0,00 & 0,00 & 0,00 & 163,00 & 168,00 & 331,00 \\
\hline Agulhão-branco & 81,50 & 62,50 & 61,00 & 67,00 & 68,50 & 0,00 & 0,00 & 340,50 \\
\hline Vermelho & 0,00 & 0,00 & 0,00 & 0,00 & 0,00 & 369,00 & 0,00 & 369,00 \\
\hline Pescada-amarela & 51,00 & 64,50 & 63,00 & 64,00 & 69,00 & 124,00 & 3,50 & 439,00 \\
\hline Congro & 0,00 & 0,00 & 0,00 & 0,00 & 0,00 & 0,00 & 443,00 & 443,00 \\
\hline Badejo & 20,50 & 30,00 & 29,00 & 30,50 & 30,00 & 85,00 & 234,50 & 459,50 \\
\hline Olhête & 81,50 & 58,00 & 62,00 & 0,00 & 68,00 & 92,00 & 114,00 & 475,50 \\
\hline Pescada & 9,50 & 82,00 & 112,00 & 101,50 & 109,00 & 72,00 & 40,50 & 526,50 \\
\hline Pacamão & 0,00 & 0,00 & 0,00 & 0,00 & 0,00 & 204,50 & 336,50 & 541,00 \\
\hline Albacora & 0,00 & 0,00 & 0,00 & 0,00 & 0,00 & 0,00 & 557,00 & 557,00 \\
\hline Albacora-bandolim & 0,00 & 0,00 & 0,00 & 0,00 & 0,00 & 263,50 & 303,50 & 567,00 \\
\hline Albacorinha & 72,50 & 118,50 & 118,00 & 129,50 & 133,50 & 0,00 & 0,00 & 572,00 \\
\hline Mero & 0,00 & 0,00 & 0,00 & 0,00 & 0,00 & 599,00 & 0,00 & 599,00 \\
\hline Pescadinha-gó & 0,00 & 0,00 & & 0,00 & 0,00 & 608,00 & 0,00 & 608,00 \\
\hline Mororo & 0,00 & 0,00 & 0,00 & 0,00 & 0,00 & 0,00 & 609,50 & 609,50 \\
\hline Pescada-cambuçu & 0,50 & 2,00 & 2,00 & 2,00 & 4,00 & 261,00 & 358,00 & 629,50 \\
\hline Ariacó & 0,00 & & 0,00 & 0,00 & 0,00 & 327,50 & 418,50 & 746,00 \\
\hline Bagre & 316,00 & 163,50 & 187,00 & 70,50 & 74,00 & 10,50 & 18,00 & 839,50 \\
\hline Olho-de-boi & 103,50 & 81,50 & 80,00 & 83,50 & 84,00 & 47,00 & 371,50 & 851,00 \\
\hline Timbira & 0,00 & 0,00 & 0,00 & 0,00 & 0,00 & 399,50 & 514,50 & 914,00 \\
\hline Bonito & 0,00 & 0,00 & 0,00 & 0,00 & 0,00 & 214,00 & 712,50 & 926,50 \\
\hline Garoupa & 39,00 & 27,50 & 22,00 & 23,00 & 24,00 & 488,50 & 350,50 & 974,50 \\
\hline Arraia & 0,00 & 257,00 & 261,50 & 283,50 & 285,00 & 0,00 & 0,00 & $1.087,00$ \\
\hline Jurupiranga & 0,00 & 0,00 & 0,00 & 0,00 & 0,00 & 575,50 & 523,00 & $1.098,50$ \\
\hline Pescada-branca & 128,00 & 118,50 & 108,50 & 111,50 & 111,00 & 4,00 & 536,00 & $1.117,50$ \\
\hline Manjuba & 41,50 & 42,00 & 43,00 & 45,00 & 42,50 & 468,50 & 440,00 & $1.122,50$ \\
\hline Cherne & 170,00 & 222,00 & 220,00 & 244,50 & 257,00 & 4,00 & 6,00 & $1.123,50$ \\
\hline Palombeta & 320,00 & 209,50 & 237,00 & 203,50 & 199,00 & 25,00 & 20,00 & $1.214,00$ \\
\hline Pescada-olhuda & 248,50 & 215,00 & 214,00 & 222,00 & 227,00 & 0,00 & 134,00 & $1.260,50$ \\
\hline Castanha & 326,50 & 211,50 & 225,50 & 219,50 & 224,00 & 58,00 & 0,00 & $1.265,00$ \\
\hline Bandeirado & 0,00 & 0,00 & 0,00 & 0,00 & 0,00 & 588,00 & 679,00 & $1.267,00$ \\
\hline Peixe-pedra & 0,00 & 0,00 & 0,00 & 0,00 & 0,00 & $1.276,50$ & 0,00 & $1.276,50$ \\
\hline Peixe-rei & 0,00 & 0,00 & 0,00 & 0,00 & 0,00 & 0,00 & $1.329,00$ & $1.329,00$ \\
\hline Tortinha & 0,00 & 0,00 & 0,00 & 0,00 & 0,00 & 723,00 & 788,50 & $1.511,50$ \\
\hline Tira-vira & 346,50 & 382,50 & 385,50 & 398,50 & 399,00 & 0,00 & 0,00 & $1.912,00$ \\
\hline Congro-rosa & 281,50 & 341,50 & 385,50 & 362,50 & 382,50 & 75,00 & 97,50 & $1.926,00$ \\
\hline
\end{tabular}

Teoria e Evidência Econômica - Ano 20, n. 42, p. 110-138, jan./jun. 2014 
Cont.

\begin{tabular}{|c|c|c|c|c|c|c|c|c|}
\hline Cabra & 21,00 & 35,50 & 35,00 & 35,00 & 34,00 & 950,00 & 910,00 & $2.020,50$ \\
\hline Goete & 435,00 & 389,00 & 392,00 & 425,00 & 432,50 & 0,00 & 0,00 & $2.073,50$ \\
\hline Abrotea & 423,00 & 292,50 & 293,00 & 311,50 & 311,00 & 297,00 & 341,00 & $2.269,00$ \\
\hline Sardinha-cascuda & 50,50 & 26,00 & 24,00 & 25,00 & 24,00 & $1.579,00$ & 593,00 & $2.321,50$ \\
\hline Namorado & 484,50 & 412,00 & 416,50 & 452,50 & 459,00 & 74,00 & 96,50 & $2.395,00$ \\
\hline Merluza & 428,50 & 386,00 & 375,50 & 403,50 & 407,00 & 468,50 & 0,00 & $2.469,00$ \\
\hline Batata & 553,00 & 462,50 & 463,50 & 509,50 & 516,00 & 0,00 & 0,00 & $2.504,50$ \\
\hline Linguado & 497,00 & 470,50 & 485,00 & 529,50 & 523,50 & 39,50 & 33,50 & $2.578,50$ \\
\hline Pescadinha-real & 477,50 & 533,00 & 540,00 & 526,00 & 529,00 & 0,00 & 0,00 & $2.605,50$ \\
\hline Savelha & 296,50 & 540,00 & 568,00 & 624,00 & 624,00 & 0,00 & 0,00 & $2.652,50$ \\
\hline Bonito-pintado & 673,50 & 490,50 & 503,50 & 499,00 & 503,00 & 0,00 & 0,00 & $2.669,50$ \\
\hline Pargo & 0,00 & 0,00 & 0,00 & 0,00 & 0,00 & $1.324,00$ & $1.516,00$ & $2.840,00$ \\
\hline Parú & 49,00 & 15,50 & 17,00 & 14,50 & 16,00 & $1.377,00$ & $1.815,00$ & $3.304,00$ \\
\hline Trilha & 768,50 & 628,50 & 637,50 & 659,00 & 667,00 & 0,00 & 0,00 & $3.360,50$ \\
\hline Cação & 387,00 & 724,50 & 726,00 & 812,00 & 820,50 & 0,00 & 0,00 & $3.470,00$ \\
\hline Espada & 910,50 & 595,00 & 617,50 & 668,00 & 677,00 & 25,50 & 69,00 & $3.562,50$ \\
\hline Albacora-branca & 52,50 & 212,00 & 211,00 & 236,00 & 239,50 & $2.067,50$ & 851,00 & $3.869,50$ \\
\hline Corcoroca & 64,00 & 39,00 & 44,00 & 40,50 & 60,00 & $3.829,00$ & 0,00 & $4.076,50$ \\
\hline Sororoca & 29,00 & 36,50 & 35,50 & 36,50 & 38,00 & $1.593,00$ & $2.336,00$ & $4.104,50$ \\
\hline Dentão & 0,00 & 0,00 & 0,00 & 0,00 & 0,00 & $2.634,50$ & $2.868,50$ & $5.503,00$ \\
\hline Galo & 543,00 & $1.028,00$ & $1.433,50$ & $1.253,50$ & $1.252,00$ & 0,00 & 0,00 & $5.510,00$ \\
\hline Pargo-rosa & $1.054,00$ & $1.202,50$ & $1.200,00$ & $1.196,50$ & $1.204,00$ & 16,00 & 23,50 & $5.896,50$ \\
\hline Peixe-voador & 0,00 & 0,00 & 0,00 & 0,00 & 0,00 & $4.172,00$ & $2.424,50$ & $6.596,50$ \\
\hline Tainha & $1.223,00$ & $1.363,50$ & $1.340,50$ & $1.380,50$ & $1.405,00$ & 0,00 & 0,00 & $6.712,50$ \\
\hline Peixe-sapo & $1.445,00$ & $1.272,00$ & $1.323,50$ & $1.390,50$ & $1.386,00$ & 0,00 & 0,00 & $6.817,00$ \\
\hline Enchova & $1.298,50$ & $1.310,50$ & $1.210,50$ & $1.288,50$ & $1.301,00$ & 744,50 & 0,00 & $7.153,50$ \\
\hline Cavala & 72,00 & 61,50 & 73,00 & 61,00 & 62,00 & $2.558,50$ & $5.066,50$ & $7.954,50$ \\
\hline Albacora-lage & $1.471,00$ & $1.444,00$ & $1.591,50$ & $1.670,00$ & $1.679,00$ & 149,00 & 164,00 & $8.168,50$ \\
\hline Xerelete & 0,00 & $2.199,00$ & $2.563,50$ & $2.140,50$ & $2.157,00$ & 10,50 & 0,00 & $9.070,50$ \\
\hline Xaréu & $2.598,00$ & 329,00 & 451,50 & 373,50 & 375,00 & $2.372,00$ & $3.131,00$ & $9.630,00$ \\
\hline Cavalinha & 311,00 & $3.134,00$ & $2.134,00$ & $2.433,00$ & $2.047,00$ & 295,50 & 376,00 & $10.730,50$ \\
\hline Bonito-cachorro & 141,00 & 155,50 & 169,50 & 170,50 & 178,00 & $5.770,00$ & $4.155,50$ & $10.740,00$ \\
\hline Dourado & $1.447,00$ & $1.584,00$ & $1.579,00$ & $1.698,50$ & $1.756,50$ & $1.422,50$ & $1.383,00$ & $10.870,50$ \\
\hline Sarda & 160,00 & 140,50 & 139,00 & 143,50 & 149,00 & $6.477,00$ & $3.670,00$ & $10.879,00$ \\
\hline Corvina & $3.346,50$ & $3.068,00$ & $3.366,50$ & $3.647,00$ & $3.213,00$ & 0,00 & 0,00 & $16.641,00$ \\
\hline Peroá & 0,00 & $4.742,50$ & $4.778,00$ & $4.733,00$ & $4.737,00$ & 106,00 & 178,50 & $19.275,00$ \\
\hline Bonito-listrado & $4.676,00$ & $4.766,00$ & $4.898,00$ & $5.117,50$ & $5.129,00$ & 453,00 & 394,50 & $25.434,00$ \\
\hline Sardinha-lage & 836,00 & $1.473,50$ & $1.410,50$ & $1.518,00$ & $1.504,00$ & $10.734,00$ & $18.737,50$ & $36.213,50$ \\
\hline Sardinha & $11.907,50$ & $8.617,00$ & $5.102,50$ & $6.061,00$ & $5.926,00$ & 24,00 & $1.365,50$ & $39.003,50$ \\
\hline Sardinha-verdadeira & $10.339,00$ & $4.498,50$ & $2.849,00$ & $16.975,00$ & $12.377,00$ & 562,50 & 40,50 & $47.641,50$ \\
\hline Xixarro & $2.449,00$ & 0,00 & 8,50 & 9,00 & 12,50 & $57.527,00$ & $75.944,50$ & $135.950,50$ \\
\hline TOTAL GERAL & $54.878,50$ & $51.969,00$ & $46.975,50$ & $62.876,50$ & $57.691,00$ & $117.996,50$ & $139.457,50$ & $531.844,50$ \\
\hline Crescimento & & $-5,30 \%$ & $-9,61 \%$ & $33,85 \%$ & $-8,25 \%$ & $104,53 \%$ & $18,19 \%$ & $22,24 \%$ \\
\hline
\end{tabular}

Fonte: Estatística da Pesca de 2000 a 2007 - Ibama - Dados trabalhado pelo autor. 


\subsection{Região Sul}

A região Sul tem apenas três estados, o Paraná que tem $98 \mathrm{~km}$, o estado de Santa Catarina com 531 km e o Rio Grande do Sul com 622 km de costa marítima. Essa região é a que apresenta uma segunda maior variedade de pesca extrativa. No estado da Paraná (Tabela 17), foram encontradas oito espécies e dessas a Pilombeta apresentou produção somente entre 2003 e 2005. Em 2007, da série histórica estudada, quatro delas tiveram queda de produção em relação ao ano anterior. Esse estado produziu 5.531 toneladas de pesca extrativa e apresentou um crescimento médio de $43,701 \%$.

Tabela 17 - Produção de pesca extrativa do Paraná

\begin{tabular}{l|c|c|c|c|c|c|c|c}
\hline \multicolumn{1}{c}{ Espécie } & 2001 & 2002 & 2003 & 2004 & 2005 & 2006 & 2007 & TOTAL \\
\hline Xixarro & 82,00 & 0,00 & 5,00 & 5,00 & 5,00 & 5,00 & 5,00 & 107,00 \\
Pescadinha-real & 9,00 & 10,00 & 20,50 & 18,00 & 19,50 & 19,00 & 19,00 & 115,00 \\
Guaravira & 15,00 & 16,50 & 32,00 & 28,00 & 30,00 & 29,00 & 29,00 & 179,50 \\
Papa-terra & 16,50 & 18,50 & 32,50 & 28,00 & 30,50 & 30,00 & 29,50 & 185,50 \\
Pilombeta & 0,00 & 0,00 & 174,50 & 163,00 & 151,00 & 0,00 & 0,00 & 488,50 \\
Corvina & 35,00 & 39,00 & 94,50 & 82,00 & 88,50 & 89,00 & 86,50 & 514,50 \\
Sardinha-cascuda & 92,00 & 102,00 & 207,50 & 160,00 & 184,00 & 183,50 & 176,00 & $1.105,00$ \\
Sardinha-verdadeira & 30,50 & 34,00 & 454,00 & 414,00 & 434,00 & 436,00 & 428,00 & $2.230,50$ \\
TOTAL GERAL & 335,00 & 280,00 & $1.128,50$ & 993,00 & $1.046,00$ & 884,50 & 864,00 & $5.531,00$ \\
Crescimento & & $-16,42 \%$ & $303,04 \%$ & $-12,01 \%$ & $5,34 \%$ & $-15,44 \%$ & $-2,32 \%$ & $43,70 \%$ \\
\hline
\end{tabular}

Fonte: Estatística da Pesca de 2000 a 2007 - Ibama - Dados trabalhado pelo autor.

No estado de Santa Catarina (Tabela 18), foram encontradas 58 espécies na pesca extrativa e as espécies Enguia tiveram produção apenas em 2002 e 2007, a espécie Galo de profundidade teve produção apenas em 2001 e a espécie Congro teve produção apenas em 2002, em 2005 e em 2007. Nas séries históricas analisadas, 14 espécies tiveram queda de produção e, em algumas, a queda foi bastante acentuada para o ano de 2007 em relação ao ano anterior. Nesse estado, também foi observado que seis espécies tiveram um aumento de produção bastante significativo de $15 \%, 46 \%, 48 \%, 53 \%, 94 \%$ e $402 \%$. O estado de Santa Catarina produziu $709.915,50$ toneladas de pesca extrativa e um crescimento médio de 5,40\%. 
Tabela 18- Produção de pesca extrativa de Santa Catarina

\begin{tabular}{|c|c|c|c|c|c|c|c|c|}
\hline \multicolumn{9}{|c|}{ Santa Catarina } \\
\hline Espécie & 2001 & 2002 & 2003 & 2004 & 2005 & 2006 & 2007 & TOTAL \\
\hline Enguia & 0,00 & 68,50 & 0,00 & 0,00 & 0,00 & 0,00 & 35,00 & 103,50 \\
\hline Olhête & 6,00 & 5,50 & 6,00 & 0,00 & 61,50 & 53,50 & 1,50 & 134,00 \\
\hline $\begin{array}{l}\text { Galo de } \\
\text { profundidade }\end{array}$ & 147,00 & 0,00 & 0,00 & 0,00 & 0,00 & 0,00 & 0,00 & 147,00 \\
\hline Congro & 0,00 & 84,00 & 0,00 & 0,00 & 82,00 & 0,00 & 10,00 & 176,00 \\
\hline Pargo-rosa & 68,50 & 50,00 & 0,00 & 20,00 & 18,50 & 34,00 & 10,50 & 201,50 \\
\hline Cherne & 78,00 & 195,50 & 78,00 & 44,00 & 27,50 & 14,00 & 25,00 & 462,00 \\
\hline Parú & 60,00 & 120,00 & 60,00 & 115,50 & 58,50 & 25,50 & 52,00 & 491,50 \\
\hline Robalo & 91,00 & 94,00 & 91,00 & 85,00 & 67,50 & 75,00 & 76,00 & 579,50 \\
\hline Cioba & 151,00 & 30,50 & 151,00 & 152,50 & 56,50 & 73,50 & 31,00 & 646,00 \\
\hline Sardinha-cascuda & 115,50 & 156,00 & 115,50 & 119,00 & 72,50 & 67,00 & 9,50 & 655,00 \\
\hline Albacora-bandolim & 145,50 & 55,00 & 145,50 & 62,00 & 73,50 & 68,50 & 111,00 & 661,00 \\
\hline Batata & 97,00 & 132,00 & 97,00 & 61,00 & 62,50 & 119,50 & 168,00 & 737,00 \\
\hline Trilha & 54,00 & 108,50 & 54,00 & 107,00 & 131,50 & 143,50 & 150,50 & 749,00 \\
\hline Corcoroca & 87,00 & 128,00 & 87,00 & 99,50 & 103,50 & 121,50 & 158,00 & 784,50 \\
\hline Pampo & 35,50 & 31,50 & 35,50 & 390,50 & 386,00 & 22,00 & 37,50 & 938,50 \\
\hline Oveva & 168,50 & 162,00 & 168,50 & 125,00 & 127,50 & 123,50 & 139,50 & $1.014,50$ \\
\hline Tira-vira & 111,50 & 157,50 & 111,50 & 71,50 & 137,00 & 86,00 & 345,50 & $1.020,50$ \\
\hline Galo & 187,50 & 371,50 & 187,50 & 213,50 & 140,00 & 0,00 & 0,00 & $1.100,00$ \\
\hline Congro-rosa & 259,50 & 373,50 & 259,50 & 89,00 & 48,50 & 60,50 & 133,00 & $1.223,50$ \\
\hline Sororoca & 176,00 & 171,50 & 176,00 & 179,50 & 181,50 & 188,50 & 190,00 & $1.263,00$ \\
\hline Peroá & 180,50 & 264,50 & 180,50 & 132,50 & 173,00 & 239,00 & 227,00 & $1.397,00$ \\
\hline Albacora-branca & 548,50 & 128,50 & 548,50 & 26,50 & 64,00 & 49,50 & 103,50 & $1.469,00$ \\
\hline Pescada-branca & 211,50 & 234,00 & 211,50 & 180,50 & 237,50 & 219,50 & 222,00 & $1.516,50$ \\
\hline Xerelete & 195,00 & 232,00 & 195,00 & 167,00 & 295,50 & 217,00 & 220,00 & $1.521,50$ \\
\hline Guaravira & 246,00 & 254,00 & 246,00 & 242,00 & 171,50 & 251,50 & 198,00 & $1.609,00$ \\
\hline Atum & 233,50 & 53,00 & 233,50 & 123,00 & 150,00 & 318,00 & 498,50 & $1.609,50$ \\
\hline Espada & 256,50 & 322,50 & 256,50 & 358,00 & 318,00 & 386,00 & 276,50 & $2.174,00$ \\
\hline Espadarte & 272,50 & 306,00 & 272,50 & 334,50 & 364,00 & 272,50 & 452,50 & $2.274,50$ \\
\hline Garapau & 139,50 & 677,50 & 139,50 & 293,50 & 822,00 & 230,00 & 147,00 & $2.449,00$ \\
\hline Xixarro & 548,50 & 180,50 & 548,50 & 15,50 & 664,50 & 294,50 & 491,00 & $2.743,00$ \\
\hline Dourado & 711,50 & 225,00 & 711,50 & 325,00 & 285,50 & 573,00 & 428,50 & $3.260,00$ \\
\hline Bonito-cachorro & 922,50 & 193,00 & 922,50 & 315,50 & 309,00 & 308,00 & 394,50 & $3.365,00$ \\
\hline Bagre & 390,00 & 552,00 & 390,00 & 454,00 & 435,00 & 633,00 & 604,00 & $3.458,00$ \\
\hline Goete & 542,00 & 648,00 & 542,00 & 687,00 & 654,00 & 972,50 & 959,00 & $5.004,50$ \\
\hline Pescadinha-real & 595,00 & $1.592,50$ & 595,00 & 526,00 & 625,50 & 432,00 & 643,50 & $5.009,50$ \\
\hline Papa-terra & 715,50 & $1.008,00$ & 715,00 & 642,50 & 691,50 & 797,50 & 838,00 & $5.408,00$ \\
\hline Cavalinha & 32,00 & 888,50 & 32,00 & $1.007,50$ & $1.222,00$ & 605,50 & $1.662,00$ & $5.449,50$ \\
\hline Pescada-amarela & $1.014,50$ & $1.197,50$ & $1.014,50$ & 82,50 & 989,00 & $1.089,00$ & 603,00 & $5.990,00$ \\
\hline Albacora-lage & 909,50 & 928,00 & 909,50 & $1.349,00$ & 603,50 & 780,00 & $1.196,00$ & $6.675,50$ \\
\hline Enchova & $1.392,00$ & 927,00 & $1.392,00$ & $1.045,00$ & 466,50 & $1.144,50$ & $1.400,00$ & $7.767,00$ \\
\hline Manjuba & $1.144,50$ & $1.059,00$ & $1.144,50$ & $1.124,00$ & $1.232,50$ & $1.194,50$ & $1.312,50$ & $8.211,50$ \\
\hline Peixe-sapo & $1.042,50$ & $2.779,50$ & $1.042,50$ & 736,50 & 954,00 & $1.017,50$ & $1.023,50$ & $8.596,00$ \\
\hline Arraia & 591,00 & $2.337,50$ & 591,00 & $1.621,00$ & $1.626,00$ & $1.684,00$ & 361,50 & $8.812,00$ \\
\hline
\end{tabular}

Teoria e Evidência Econômica - Ano 20, n. 42, p. 110-138, jan./jun. 2014 
Cont.

\begin{tabular}{l|c|c|c|c|c|c|c|c}
\hline Linguado & $1.479,50$ & $2.134,00$ & $1.478,50$ & 994,00 & $1.567,50$ & $1.387,50$ & $1.754,00$ & $10.795,00$ \\
Pescada-olhuda & $3.324,00$ & 6,50 & $3.324,00$ & $1.453,00$ & $2.664,00$ & 18,50 & 19,50 & $10.809,50$ \\
Palombeta & 959,50 & $1.870,00$ & 959,50 & $1.453,50$ & $1.938,50$ & $1.870,50$ & $1.784,00$ & $10.835,50$ \\
Merluza & $2.296,00$ & $3.065,50$ & $2.296,00$ & 720,00 & 830,00 & $1.053,00$ & $1.284,00$ & $11.544,50$ \\
Pescada & 631,50 & $1.105,00$ & 631,50 & 686,00 & 517,00 & $3.496,50$ & $5.129,50$ & $12.197,00$ \\
Cação & $2.638,00$ & $3.324,00$ & $2.638,00$ & $2.537,50$ & $2.449,00$ & $2.051,00$ & $3.053,00$ & $18.690,50$ \\
Tainha & $2.777,50$ & $1.622,00$ & $2.777,50$ & $2.958,00$ & $3.458,50$ & $1.328,00$ & $6.675,50$ & $21.597,00$ \\
Cabra & $1.992,00$ & $4.233,50$ & $1.992,00$ & $2.904,00$ & $3.470,50$ & $4.117,00$ & $4.397,00$ & $23.106,00$ \\
Abrotea & $4.075,00$ & $6.603,00$ & $4.075,00$ & $2.333,50$ & $3.286,00$ & $3.495,50$ & $5.350,00$ & $29.218,00$ \\
Sardinha-lage & $5.043,00$ & $2.320,50$ & $5.043,00$ & $4.234,00$ & $3.123,50$ & $6.059,50$ & $11.784,50$ & $37.608,00$ \\
Castanha & $5.594,50$ & $6.978,50$ & $5.594,50$ & $5.656,00$ & $4.224,50$ & $5.442,50$ & $6.041,50$ & $39.532,00$ \\
Bonito-listrado & $12.358,50$ & $13.880,00$ & $12.358,50$ & $15.773,50$ & $15.276,50$ & $15.095,00$ & $17.360,00$ & $102.102,00$ \\
Corvina & $14.763,50$ & $15.098,50$ & $14.763,50$ & $12.140,00$ & $14.062,50$ & $20.123,00$ & $18.180,00$ & $109.131,00$ \\
Sardinha-verdadeira & $18.132,00$ & $10.392,50$ & $18.132,00$ & $28.574,00$ & $27.881,00$ & $31.049,00$ & $25.179,00$ & $159.339,50$ \\
TOTAL GERAL & $91.005,50$ & $92.323,50$ & $90.788,50$ & $96.198,50$ & $99.971,50$ & $111.645,00$ & $123.983,00$ & $705.915,50$ \\
Crescimento & & $1,45 \%$ & $-1,66 \%$ & $5,96 \%$ & $3,92 \%$ & $11,68 \%$ & $11,05 \%$ & $5,40 \%$ \\
\hline
\end{tabular}

Fonte: Estatística da Pesca de 2000 a 2007 - Ibama - Dados trabalhado pelo autor.

Analisando as séries históricas de todas as regiões (Tabela 19), observa-se que o Norte e o Nordeste juntos têm 11 estados e um total de $4.477 \mathrm{~km}$ de litoral, representando mais de $45 \%$ do litoral Sudeste e Sul juntos. O Norte e Nordeste do Brasil apresentam baixa produtividade. O Norte, com apenas dois estados, consegue produzir 95,65\% do total da produção do Nordeste. As séries históricas do Sudeste e do Sul mostram que somente o estado de Santa Catarina produz 80\% do total do Sudeste, ainda que o estado do Rio de Janeiro tenha a maior variedade de espécie de pesca extrativa.

Tabela 19 - Pesca extrativa - regiões

\begin{tabular}{|c|c|c|c|}
\hline \multicolumn{3}{|c|}{ Região Nordeste } & Litoral \\
\hline $\begin{array}{l}\text { Alagoas } \\
\text { Bahia } \\
\text { Ceará } \\
\text { Maranhão } \\
\text { Paraíba } \\
\text { Pernambuco } \\
\text { Piauí } \\
\text { Rio Grande do Norte } \\
\text { Sergipe }\end{array}$ & $\begin{array}{c}32.203,00 \\
184.456,00 \\
52.526,50 \\
124.498,50 \\
1.484,00 \\
8.412,00 \\
593,00 \\
40.807,00 \\
2.623,50 \\
\end{array}$ & $447.603,50$ & $\begin{array}{l}229 \mathrm{~km} \\
932 \mathrm{~km} \\
573 \mathrm{~km} \\
640 \mathrm{~km} \\
117 \mathrm{~km} \\
187 \mathrm{~km} \\
66 \mathrm{~km} \\
410 \mathrm{~km} \\
163 \mathrm{~km}\end{array}$ \\
\hline \multicolumn{4}{|c|}{ Região Norte } \\
\hline $\begin{array}{l}\text { Amapá } \\
\text { Pará }\end{array}$ & $\begin{array}{c}33.687,00 \\
395.265,50\end{array}$ & $428.952,50$ & $\begin{array}{l}598 \mathrm{~km} \\
562 \mathrm{~km}\end{array}$ \\
\hline \multicolumn{4}{|c|}{ Região Sudeste } \\
\hline $\begin{array}{l}\text { Espírito Santo } \\
\text { Ri de Janeiro } \\
\text { São Paulo }\end{array}$ & $\begin{array}{c}92.489,00 \\
531.844,50 \\
160.345,50 \\
\end{array}$ & $784.679,00$ & $\begin{array}{l}392 \mathrm{~km} \\
636 \mathrm{~km} \\
622 \mathrm{~km} \\
\end{array}$ \\
\hline \multicolumn{4}{|c|}{ Região Sul } \\
\hline $\begin{array}{l}\text { Paraná } \\
\text { Santa Catarina } \\
\text { Rio Grande do Sul }\end{array}$ & $\begin{array}{c}5.531,00 \\
709.915,50 \\
234.198,50 \\
\end{array}$ & $949.645,00$ & $\begin{array}{c}98 \mathrm{~km} \\
531 \mathrm{~km} \\
622 \mathrm{~km} \\
\end{array}$ \\
\hline
\end{tabular}

Fonte: Estatística da Pesca de 2000 a 2007 - Ibama - Dados trabalhado pelo autor. 


\section{Conclusão}

A atividade pesqueira envolve uma série de fatores (histórico-culturais, ambientais, sociais, políticos e econômicos) e, nesse sentido, aponta-se a necessidade de articular conhecimentos, saberes e ciências para propiciar uma visão mais integrada da pesca e perceber a riqueza e as nuances desse universo.

Considerando que a extensão marítima da costa brasileira é de $7.378 \mathrm{~km} \mathrm{e}$ produziu 2.868.225,00 toneladas de pescado, verifica-se que ainda há regiões com baixa produtividade. Mas no que diz respeito à riqueza de espécie de pescado, encontramos na região Nordeste 54 espécie, na região Norte 40, na região Sudeste 97 espécies e, na região Sul, 62 de espécies. No que tange a políticas públicas para o fomente da atividade, o governo federal poderá concluir que é necessário investir mais recursos humanos e tecnológicos e modernizar todo o processo logístico da região Norte e Nordeste, de modo a torna-las mais produtivas. Porém, as regiões Sul e Sudeste, também precisam de melhores incentivos para poder continuar com a alta produtividade e melhorar toda a logística da pesca na região.

De outro modo, também é necessário pesquisar as causas da baixa produtividade da região Norte e Nordeste, procurando desvendar quais os fatores de sucesso da região sul e sudeste. As regiões com melhor desempenho teriam melhores embarcações, melhores técnicas, melhores apetrechos, ou apresentariam uma matriz socioeconômica melhor, ou, ainda, se o fator de sucesso está baseado na riqueza das variedades de espécies de pescado.

Poderá ser com base no resultado desses questionamentos que se poderá esclarecer a baixa produtividade da região Norte e Nordeste e trabalhar no equacionamento e na solução dessas questões. 


\title{
The state of small-scale fishing in brazilian regions
}

\begin{abstract}
Fishing plays an important role in the Brazilian economy; offers hand labor, income, and food for the population. But statistics on marine fisheries in Brazil are insufficient to be an activity primarily extractive, decentralized and surrounded by great informality, being one of the main problems the quantification of its economic importance. Therefore, this paper gathers and analyzes data from the fish production in the Brazilian regions, the time from 2000 to 2007 . The results are used to place the national context of fishery production, which can be observed at regions that produced, highlighting for artisanal fisheries in the North and Northeast.
\end{abstract}

Keywords: Fishing. Brazilian Regions. Statistics.

\section{El estado de la pesca artesanal en regiones de Brasil}

\section{Resumen}

Pesca desempeña un papel importante en la economía brasileña, ofrece la mano de obra, ingresos y alimentos para la población. Sin embargo, las estadísticas sobre la pesca marina en Brasil son insuficientes para una actividad fundamentalmente extractiva, descentralizado y rodeado por una gran informalidad, siendo uno de los principales problemas de la cuantificación de su importancia económica. Por lo tanto, este documento recoge y analiza los datos de la producción pesquera en las regiones brasileñas, el tiempo de 2000 a 2007. Los resultados se utilizan para colocar el contexto nacional de la producción pesquera, que se puede observar en las regiones que producen, destacando la pesca artesanal en el norte y el noreste..

Palabras clave: Pesca. Regiones Brasileñas. Estadística. 


\section{Referências}

ARAUJO, L. Forte velho: da subsistência a dependência industrial. Universidade Federal da Paraíba, 1992

BOLETIM Estatístico da Pesca e Aquicultura. Ministério da Pesca e Aquicultura, Brasil, 2008-2009.

. Ministério da Pesca e Aquicultura, Brasil, 2010.

CASTELLO, J. P.; HAIMOVICI, M. Simpósio da FURG sobre Pesquisa Pesqueira: comentários e recomendações. SIMPÓSIO SOBRE PESQUISA PESQUEIRA DA FUNDAÇÃO UNIVERSIDADE DO RIO GRANDE. 1991, Atlântica, Rio Grande, v. 13, n. 1, p. 5-10. Anais...

CASTELLO, Jorge Pablo. Gestão sustentável dos recursos pesqueiros, isto é realmente possível? In: PANAMJAS - Pan American Journal of Aquatic Sciencies, p. 47-52, 2007.

CAVALLI, Ronaldo Olivera; FERREIRA, Jaime Fernando. O futuro da Pesca da Aquicultura Marinha no Brasil: a Maricultura. Ciência e Cultura [online]. n. 3, p. 38-39, 2010.

VIANNA, Marcelo (Org.). Diagnóstico da cadeia produtiva da pesca marítima no Estado do Rio de Janeiro: relatório de pesquisa. Rio de Janeiro: Faerj; Sebrae - RJ, 2009.

DIAS NETO, J.; MESQUITA, J. X. Potencialidade e explotação dos recursos pesqueiros do Brasil. Ciência e Cultura, São Paulo, v. 40, n. 5, p. 427-441. 1988.

DIAS NETO, Jose. Gestão de recursos pesqueiros marinhos no Brasil. Brasília: Ibama, 2010.

DIEGUES, A. C. Pesca e marginalização no litoral paulista, 1973. Dissertação (Mestrado) - NUPAUB/CEMAR. Universidade de São Paulo. USP. São Paulo, SP.

DORNELLES, L. D. C. Diagnóstico da Pesca Marítima do Brasil: Ibama, 1996. (Coleção Meio Ambiente, Série Estudos Pesca, 20).

IBAMA. Estatística da pesca 2000. Brasil. Grandes Regiões e Unidades da Federação. Ibama, 2000.

2001.

Estatística da pesca 2001. Brasil. Grandes Regiões e Unidades da Federação. Ibama,

_. Estatística da pesca 2002. Brasil. Grandes Regiões e Unidades da Federação. Ibama, 2002.

2003.

2004.

Estatística da pesca 2003. Brasil. Grandes Regiões e Unidades da Federação. Ibama,

Estatística da pesca 2004. Brasil. Grandes Regiões e Unidades da Federação. Ibama,

Estatística da pesca 2005. Brasil. Grandes Regiões e Unidades da Federação. Ibama, 2005.

2006.

Estatística da pesca 2006. Brasil. Grandes Regiões e Unidades da Federação. Ibama, Estatística da pesca 2007. Brasil. Grandes Regiões e Unidades da Federação. Ibama, 2007. 
FAO. El estado mundial de la pesca e acuicultura - 1988. Roma: FAO, 1999.

. El estado mundial de la pesca y la Acuicultura. Rome: FAO, 2009.

. The state of world fisheries and aquaculture 2012. Rome. 2012.

HAZIN, Fábio Hissa Vieira. O Futuro da Pesca da Aquicultura Marinha no Brasil: a Pesca Oceânica. Ciência e Cultura [online], v. 62, n. 3, p. 36-37, 2010.

MARRUL FILHO, Simão. Crise e sustentabilidade dos recursos pesqueiros, Tese (Mestrado em Desenvolvimento Sustentável) - Brasília, UNB, 2001.

MATSUURA, Y. Explotação pesqueira. In: MMA. Os ecossistemas brasileiros e os principais macrovetores de desenvolvimento. Subsídios ao planejamento da gestão ambiental. Brasília: Ministério do Meio Ambiente, dos Recursos Hídricos e da Amazônia Legal. p. 42-48. 1995.

MELQUIADES Pinto. Recursos pesqueiros estuarinos e marinhos do Brasil. Fortaleza: EUFC, 1997.

MESCHKAT, Arno. Aquacultura e pesca em águas interiores no Brasil. Rio de Janeiro, Programa de Pesquisa de Desenvolvimento Pesqueiro do Brasil, PNUD/FAO - Ministério da Agricultura/ Sudepe, 1975.

PAIVA, Melquiades Pinto. Administração Pesqueira no Brasil. Rio de Janeiro: Interciencia, 2004.

MEDEIROS, Rodrigo; IRVING, Marta de Azevedo. Áreas protegidas e inclusão social: tendências e perspectivas, Rio de Janeiro, v. 3, n. 1. 2007.

SANTOS, J. O papel da administração pesqueira na gestão do subsector artesanal em Moçambique: o presente e modelos para o futuro. In: Notas Técnicas DNAP. 2008 Direção Nacional de Administração Pesqueira - Ministério da Pesca: Maputo, Moçambique.

HAINOVICI, Manuel (Org.). Sistemas pesqueiros marinhos e estuarinos no Brasil: caracterização e análise da sustentabilidade. Rio Grande: Ed. da FURG, 2011.

STATISTICS AND INFORMATION SERVICE OF THE FISHERIES AND AQUACULTURE DEPARTMENT/SERVICE, FAO yearbook. Fishery and Aquaculture Statistics. 2010/FAO annuaire. Statistiques, 2010. Rome, FAO. 78 p.

YESAKI, M., 1973. Sumário dos levantamentos de pesca exploratória ao largo da costa sul do Brasil e estimativa da biomassa de peixe demersal e potencial pesqueiro. Documentos Técnicos SUDEPE-PDP/T, Rio de Janeiro, v. 1, p. 1-27. 